Published in final edited form as:

J Am Chem Soc. 2019 December 18; 141(50): 19677-19687. doi:10.1021/jacs.9b07883.

\title{
1,3,5-Triazine-cored maltoside amphiphiles for membrane protein extraction and stabilization
}

\author{
Lubna Ghani $^{\mathrm{a}}$, Chastine F. Munk ${ }^{\mathrm{b}}$, Xiang Zhang ${ }^{\mathrm{c}}$, Satoshi Katsube ${ }^{\mathrm{d}}$, Yang Du ${ }^{\mathrm{e}, \dagger}$, Cristina \\ Cecchetti $^{f}$, Weijiao Huang ${ }^{e}$, Hyoung Eun Bae ${ }^{a}$, Savvas Saouros ${ }^{f}$, Muhammad Ehsan $^{a}, \dagger$, Lan \\ Guan $^{d}$, Xiangyu Liu ${ }^{c}$, Claus J. Loland ${ }^{b}$, Brian K. Kobilka ${ }^{e}$, Bernadette Byrne ${ }^{f}$, Pil Seok \\ Chae $^{a}$
}

aDepartment of Bionanotechnology, Hanyang University, Ansan 155-88, Korea

bDepartment of Neuroscience, University of Copenhagen, Copenhagen, DK-2200, Denmark

'Beijing Advanced Innovation Center for Structural Biology, School of Medicine, School of Pharmaceutical Sciences, Tsinghua University, 100084 Beijing, China

${ }^{d}$ Department of Cell Physiology and Molecular Biophysics, Center for Membrane Protein Research, School of Medicine, Texas Tech University Health Sciences Center, Lubbock, Texas 79430, USA

eDepartment of Molecular and Cellular Physiology, Stanford University, California 94305, USA

fDepartment of Life Sciences, Imperial College London, London, SW7 2AZ, UK

\begin{abstract}
Despite the major biological and pharmacological significance, structural and functional study of membrane proteins remains a significant challenge. A main issue is the isolation of these proteins in a stable and functional state from native lipid membranes. Detergents are amphiphilic compounds widely used to extract membrane proteins from the native membranes and maintain them in a stable form during downstream analysis. However, due to limitations of conventional detergents it is essential to develop novel amphiphiles with optimal properties for protein stability in order to advance membrane protein research. Here we designed and synthesized 1,3,5-triazinecored dimaltoside amphiphiles derived from cyanuric chloride. By introducing variations in the alkyl chain linkage (ether/thioether) and an amine-functionalized diol linker (serinol/ diethanolamine), we prepared two sets of 1,3,5-triazine-based detergents. When tested with several model membrane proteins, these agents showed remarkable efficacy in stabilizing three
\end{abstract}

\footnotetext{
Corresponding Author: pchae@hanyang.ac.kr.

†Present Addresses: M.E.: Department of Chemistry, Mirpur University of Science \& Technology (MUST), Mirpur-10250 (AJK), Pakistan.

Y.D.: School of Life and Health Sciences, Chinese University of Hong Kong, 2001 Longxiang Ave, Shenzhen, Guangdong 518172, China.

Supporting Information

Electronic Supplementary Information (ESI) available free of charge via the internet at http://pubs.acs.org, including Figures S1-14, Table S1, supplementary methods for protein stability assays and detergent synthetic protocols and characterizations.

Conflicts of interest

The authors declare the following competing financial interest(s): P.S.C. and L.G. (Hanyang university) are inventors on a patent application that covers the TSM/TEM agents.
} 
transporters and two G protein-coupled receptors. Detergent behavior substantially varied depending on the detergent structural variation, allowing us to explore detergent structureproperty-efficacy relationships. The 1,3,5-triazine-based detergents introduced here have significant potential for membrane protein study as a consequence of their structural diversity and universal stabilization efficacy for several membrane proteins.

\section{Graphical Abstract}

\section{MOR stability}

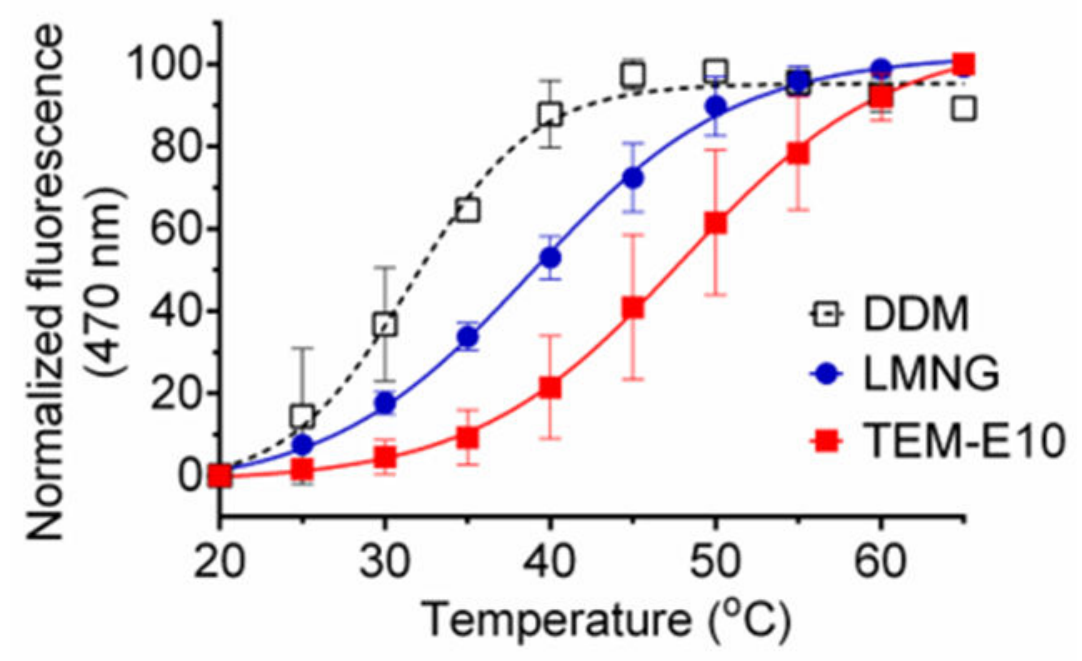

\section{Keywords}

triazine; membrane proteins; protein stabilization; amphiphile design; protein structure

\section{Introduction}

Membrane proteins are therapeutically-important biomacromolecules that play crucial roles in normal cellular function and in the development of a range of pathophysiological conditions. Accordingly, many research groups have made intense efforts to structurally characterize membrane proteins in order to provide a basis for rational drug design. Currently, around $60 \%$ of all commercial drug molecules target these membrane-inserted proteins. Among these biomacromolecules, G protein-coupled receptors (GPCRs), nuclear receptors or ion channels are currently the main targets of both small molecule and biological drugs. ${ }^{1}$ Atomic resolution structures of proteins have revolutionized our understanding of many processes that underpin biological functions. The high resolution structural analysis remained intractable for membrane proteins until 1985 when Deisenhofer et.al., successfully obtained a detailed structure of the photosynthetic reaction center complex in detergent via X-ray crystallography. ${ }^{2}$ Despite major efforts, obtaining highresolution structures of this class of biomacromolecules remains challenging, as illustrated by the protein data bank where unique membrane proteins constitute around $2 \%$ of the currently known protein structures. ${ }^{3}$ 
Extraction of membrane proteins from the native lipid environments and their effective isolation requires detergents. Detergents comprise hydrophobic and hydrophilic groups and are thus amphiphilic. These groups interact with the hydrophobic and hydrophilic surfaces of membrane proteins, resultantly endowing water-solubility to protein-detergent complexes (PDCs) by shielding the hydrophobic segments. Detergents are the most commonly used lipid surrogate and it is essential to find a detergent which packs optimally around a target membrane protein. A large number of classical detergents are available, but only a small number, including DDM ( $n$-dodecyl- $\beta$-D-maltoside), DM ( $n$-decyl- $\beta$-D-maltoside) and OG ( $n$-octyl- $\beta$-D-glucoside) are broadly used for membrane protein study (Fig. 1) ${ }^{4-5}$ In contrast to the large diversity of biological functions and three dimensional architectures of membrane proteins, classical detergents have a canonical structure comprising a single hydrophobic chain and hydrophilic headgroup. This narrow structural diversity of classical detergents is likely responsible for the slow progress in membrane protein structural study. ${ }^{4}$ Thus, large efforts have been made over the past two decades to develop novel classes of amphiphiles with distinct architectures. ${ }^{6}$ As representatives, large systems such as nanodiscs (NDs), ${ }^{7 \mathrm{a}}$ amphiphilic polymers [amphipols (APols), styrene/maleic acid (SMA) copolymer], ${ }^{7 \mathrm{~b}-\mathrm{e}}$ peptide detergents [lipopeptide detergents (LPDs) and $\beta$-peptides (BPs)] ${ }^{8 \mathrm{a}, \mathrm{b}}$ have been shown to maintain several membrane proteins in the native conformations. However, these novel systems are not often amenable to protein extraction and, more importantly, are broadly unsuitable to protein crystallization with a few exceptions (e.g., SMA). ${ }^{7 \mathrm{e}}$ As an alternative strategy, small amphiphilic molecules have been devised with representatives including neopentyl glycol (NG) amphiphiles [glucose/maltose neopentylglycols (GNGs/MNGs) and neopentyl glycol triglucosides (NDTs)], ${ }^{9}$ hemifluorinated surfactants (HFSs), ${ }^{10}$ facial amphiphiles (FAs), ${ }^{11}$ tripod amphiphiles (TPAs),${ }^{12}$ mannitolbased amphiphiles (MNAs), ${ }^{13}$ xylene or mesitylene-linked amphiphiles (XMAs/MGAs), ${ }^{14}$ pentasaccharide-bearing amphiphiles (PSEs), ${ }^{15}$ achiral/chiral amphiphiles [butane-tetraolbased maltosides (BTMs) and norbornane ring-based maltosides (NBMs)], ${ }^{16}$ and dendronic group-containing trimaltoside amphiphiles (DTMs). ${ }^{17}$ Among these novel detergents, GNG-3 (commercial name: OGNG; Fig. 1) has enabled the high-resolution structural determinations of several membrane proteins, as exemplified with a sodium-pumping pyrophosphatase, and human aquaporin 2 (AQP2). ${ }^{18}$ Furthermore, MNG-3 (commercial name: LMNG; Fig. 1) was key for the structural elucidation of many GPCRs over the past seven years. ${ }^{19}$ These success stories highlight the potential of small novel amphiphiles. Despite the substantial contribution to membrane protein structure determination, OGNG or LMNG do not stabilize all membrane proteins. Indeed, it is widely accepted that no single detergent can be a suitable solubilization and crystallization agent for all or even many membrane proteins. Thus, we still need new amphiphilic agents with marked protein stabilization efficacy for multiple membrane proteins. In the study presented here, we have designed and synthesized two sets of 1,3,5-triazine-cored detergents with two alkyl chains and a branched dimaltoside head group, designated the 1,3,5-triazine-cored maltosides. Each set contains either serinol or diethanolamine as the linker used to connect the maltoside headgroup with the 1,3,5-triazine ring. These agents were evaluated with several model membrane proteins and their efficacy compared to protein solubilization and stabilization with DDM or LMNG. This study revealed several promising detergents, especially TEM- 
E10 and TEM-T9, that endow a range of membrane proteins with markedly enhanced stability compared to DDM and LMNG.

\section{Results}

\section{Structural and physical characterizations of new detergents}

The novel amphiphiles were constructed using a 1,3,5-triazine ring in the central region, which was flanked by detergent head and tail groups (Fig. 1). The aromatic ring located in the central region likely limits flexibility of the new detergents. In addition, this heterocyclic aromatic ring should dictate the direction/positions of the individual head and tail groups, a feature which plays a crucial role in detergent micellar packing which in turn is critical for membrane protein stabilization. Of note, 1,3,5-triazine (sym-triazine), a heterocyclic aromatic ring with three nitrogen atoms, is among the most ideal scaffolds for combinatorial library construction mainly because of its convenient structural variation. Consequently, the sym-triazine scaffold is widely used in the pharmaceutical industry and is found in many potent, biologically active molecules including ones used in anticancer, ${ }^{20-23}$ antimicrobial, 24,25 and antiviral therapies. ${ }^{26}$ However, to date this scaffold has not been incorporated into detergent structure with a view to producing molecules suitable for membrane protein study.

The maltoside headgroup was conjugated into the central ring via the use of an aminefunctionalized diol linker; either a serinol (TSMs) or diethanolamine (DEA) (TEMs) linker (Fig. 1). The serinol linker is relatively rigid while the DEA linker is more flexible and lacks any potential hydrogen bond donor. The serinol and DEA linkers were functionalized with primary and secondary amines, respectively. Thus, the TSMs and TEMs also differ in the directions of the maltoside headgroup relative to the central ring. Therefore, the linker variation affects both detergent flexibility and detergent geometry. The two alkyl chains introduced as the hydrophobic group were conjugated to the central ring via ether (E) or thioether (T) linkage, yielding two subsets of each set of the new detergents: TSM-E/T and TEM-E/T. These two alkyl chain linkages (i.e., ether and thioether) differ in their hydrophobicity; the thioether bond (C-S) is more hydrophobic than the ether bond (C-O), and is almost comparable to a $\mathrm{C}-\mathrm{C}$ bond in this respect. In addition, the $\mathrm{C}-\mathrm{S}$ and $\mathrm{C}-\mathrm{O}$ groups have different bond lengths, generating variation in the detergent hydrophobic length.

When we estimated the hydrophobic lengths of the new agents from their extended or energy-minimized conformations, the thioether version (e.g., TEM-T9) gave a hydrophobic length longer than the ether analog (e.g., TEM-E9) by 0.2-0.3 $\AA$ (Figure S1). The detergent hydrophobic length was principally varied using different alkyl chains from $\mathrm{C} 7$ (heptyl) to C11 (undecyl) for each set of new detergents. Thus, the different linkages (ether and thioether) serve as a way to fine-tune the detergent hydrophobic length, potentially allowing greater compatibility with the hydrophobic widths of individual membrane proteins ( $28-32$ $\AA$ ). In addition, the variations in alkyl chain linkage (ether/thioether) and alkyl chain length (C7/C8/C9/C10/C11) introduced here influence the hydrophile-lipophile balance (HLB) essential for detergent efficacy for protein extraction and stabilization. ${ }^{12,27}$ Of note, the thioether linkage used for the TSM/TEM-Ts is rarely exploited in novel detergent design although some studies showed that thioether-bearing detergents [e.g., n-octyl- $\beta$-D- 
thioglucoside (OTG)] are superior to the ether analog (OG) in membrane protein solubilization and stabilization. ${ }^{28}$

The new agents are efficiently prepared by four high-yielding synthetic steps: 1) dialkylation, 2) coupling to an amine-functionalized diol linker (serinol/DEA), 3) AgOTfpromoted glycosylation and 4) global deprotection of multiple benzoyl groups (Scheme 1). The two hydrophobic chains were first attached to the 1,3,5-triazine ring using an inexpensive starting material, 2,4,6-trichloro-1,3,5-triazine. The dialkylation reaction with an alkanol was carried out under mild basic conditions $\left(\mathrm{NaHCO}_{3}\right)$, giving the dialkylated products (A) with the ether linkage with $\backsim 50 \%$ yields. The corresponding reaction with an alkanethiol, where diisopropylethylamine was used as a base, generated the dialkylated products with the thioether linkage (A) with high synthetic yields ( $\sim 80 \%)$. The resulting dialkylated 1,3,5-triazene derivatives (A) were coupled with an amine-functionalized linker (serinol/DEA) to produce the diol-functionalized triazine compounds ( $\mathbf{B}$ or $\mathbf{C}$; yield $\sim 80 \%$ )), used as substrates for $\beta$-selective glycosylation (yield $\sim 85 \%$ ). Finally, a global deprotection of the glycosylated products yielded the 1,3,5-triazine-cored amphiphiles with the serinol (TSMs) or DEA linker (TEMs) (yield 90\%) (see ESI Schemes 1 \& 2).

The chemical shifts and coupling constants estimated from the individual ${ }^{1} \mathrm{H}$ NMR spectra suggest the high anomeric purities of the newly synthesized amphiphiles (Figure S2).

Glycosylation promoted by the use of silver triflate was used as a key step to stereoselectively introduce the maltoside headgroup into the diol intermediates $(\mathbf{B}$ or $\mathbf{C})$. The anomeric protons $\left(\mathrm{H}_{\mathrm{a}}\right)$ of TSM-T9 produce two peaks as individual doublets at 4.35 and $4.37 \mathrm{ppm}$, respectively. In addition, these anomeric protons $\left(\mathrm{H}_{\mathrm{a}}\right)$ interact with their neighboring protons $(\mathrm{H})$, with a coupling constant $\left({ }^{3} J_{\mathrm{aa}}\right)$ of $8.0 \mathrm{~Hz}$, revealing that $\beta$-selective glycosylation occurred exclusively. We also observed another doublet peak at $5.16 \mathrm{ppm}$ with a smaller coupling constant $\left({ }^{3} J_{\mathrm{ae}}=4.0 \mathrm{~Hz}\right)$, which corresponds to the a-anomeric protons $\left(\mathrm{H}_{\mathrm{e}}\right)$ in the second glucose unit of the TSMs and TEMs (Fig. 2a and S2 $\dagger$ ). A DEA linkerbearing detergent (e.g., TEM-T9) also gave similar chemical shifts and the same coupling constants for these anomeric protons. However, the two $\alpha-/ \beta$-anomeric protons of the TSMs and TEMs differently behaved in terms of the chemical shifts and peak patterns. TSM-T9 gave two doublet peaks for these protons, while a single doublet peak was observed for each anomeric proton $\left(\mathrm{H}_{\mathrm{a}}\right.$ or $\left.\mathrm{H}_{\mathrm{e}}\right)$ of TEM-T9 (Fig. 2a). This difference is likely due to the asymmetric or symmetric nature of the detergent linker (serinol or DEA). The two detergents (TSM-T9 and TEM-T9) were further characterized via 2D-NOESY experiments. In order to have a peak corresponding to the NH proton of the serinol linker, DMSO- $\mathrm{d}_{6}$ rather than $\mathrm{CD}_{3} \mathrm{OD}$ was used as an NMR solvent. This amine proton peak $\left(-\mathrm{NH}_{\mathrm{d}}\right)$ of TSMT9 appeared at $7.76 \mathrm{ppm}$ and showed strong NOE correlation signals with the neighboring protons $\left(\mathrm{H}_{\mathrm{a}}, \mathrm{H}_{\mathrm{b}}\right.$ and $\mathrm{H}_{\mathrm{c}}$ ) (Fig. 2b). No corresponding signals were observed for TEM-T9 due to the absence of the - $\mathrm{NH}$ group in the linker region. We also detected correlation signals of the anomeric protons $\left(\mathrm{H}_{\mathrm{a}}\right)$ with the neighboring protons $\left(\mathrm{H}_{\mathrm{b}}\right.$ and $\left.\mathrm{H}_{\mathrm{c}}\right)$ in both linkers of the detergents (Fig. 2b,c).

High water-solubility up to $10 \%$ was found in all new detergents introduced here except for the $\mathrm{C} 10$ and $\mathrm{C} 11$ versions of both sets (TSMs and TEMs) which gave water solubilities of 5 
and $1 \%$, respectively. The new detergents retained clear solutions during a two-month incubation at room temperature. Micelles formed by the TSMs and TEMs were characterized critical micelle concentrations (CMCs) and micelle size, both of which were estimated via fluorophore inclusion ${ }^{29}$ and dynamic light scattering (DLS) experiments, respectively. Table 1 presents the summarized results of these characterizations. The new agents started to form micelles at relatively low detergent concentrations (1 to $40 \mu \mathrm{M})$ compared to DDM $(170 \mu \mathrm{M})$. Due to an increase in detergent hydrophobicity, longer alkyl chain detergents gave the smaller CMCs for both sets (TSMs and TEMs). For example, the CMCs of the TSMs were reduced from 40 to 10 to $2 \mu \mathrm{M}$ when their alkyl chain lengths were increased from $\mathrm{C} 7$ to $\mathrm{C} 9$ to $\mathrm{C} 11$. The TSMs gave higher CMCs than the TEMs. In addition, the new detergents with the thioether linkage (TSM-Ts and TEM-Ts) had substantially lower CMCs than the ether counterparts (TSM-Es and TEM-Es), mainly due to the higher hydrophobicity of the thioether bond compared to the ether bond. For instance, TSM-T7 gave a CMC of $10 \mu \mathrm{M}$, four times lower than TSM-E7 $(40 \mu \mathrm{M})$. The micelle sizes of the TSMs and TEMs were proportional to their alkyl chain length. For the TSM-Es, for example, micelle size increased from 3.4 (C7) to 4.0 (C9) to $56.2 \mathrm{~nm}$ (C11). Interestingly, micelles formed by the TEMs are smaller than those formed by the TSM analogs, as exemplified by TEM-E10 $(4.5 \mathrm{~nm})$ and TSM-E10 $(8.7 \mathrm{~nm})$. The variation in the linker (serinol/DEA) explains this difference in micelle size. Detergent micelle size also varied depending on alkyl chain linkage (ether vs thioether). The thioether versions formed micelles slightly larger than the ether analogs. For example, TSM-E7 and TSM-T7 gave micelle size $\left(R_{\mathrm{h}}\right)$ of 3.4 and $3.6 \mathrm{~nm}$, respectively. This result suggests a large volume of the hydrophobic group relative to that of the hydrophilic group for the thioether version, associated with differences in both bond length (C-S $v S \mathrm{C}-\mathrm{O}$ ) and atom size (sulfur $v s$ oxygen). Analysis of the micelles revealed a highly homogeneous population. Both numberand volume-weighted DLS profiles yielded a narrow and single set of distribution for each individual detergent (Figure S3 \& S4 $\dagger$ ). Large micelles with a size of 100 1000 nm were observed in the intensity-weighted distribution, likely due to the ultrahigh sensitivity of scattered light intensity to a large particle (Figure S5†). ${ }^{30}$

\section{Detergent comparison study with multiple membrane proteins}

The suitability of the TSMs and TEMs for membrane protein study was first investigated with the leucine transporter (LeuT). ${ }^{31}$ The transporter purified in DDM was used for detergent exchange from DDM to the individual TSMs, TEMs or DDM attained by sample dilution. Each detergent was tested at $0.04 \mathrm{wt} \%$ above the individual CMCs $(\mathrm{CMC}+0.04 \mathrm{wt}$ $\%)$ and detergent exchange was performed for 16 hours. Protein stability that was measured using scintillation proximity assay (SPA) ${ }^{32}$ was monitored at regular time points during a 13-day incubation at room temperature. After detergent exchange, DDM-solubilized LeuT exhibited a rapid decrease in substrate binding ability, although initial activity was high. In contrast, almost every new detergent tested here was substantially better than DDM at maintaining transporter activity (Fig. 3 and $\mathrm{S} 6 \dagger$ ). The highest binding of $\left[{ }^{3} \mathrm{H}\right]$-Leu within the 13-day period was observed in the new detergents with intermediate alkyl chain lengths (TSM-E8/T9/T10 and TEM-E10/T8/T9/T10), while TSM-E7 and TEM-E7 with the shortest chain length (C7) were much poorer at stabilizing the transporter long-term yet still better than DDM. With very few exceptions, the TEMs with the DEA linker were more effective 
than the serinol linker variants (TSMs), indicating a favorable role of DEA relative to serinol as a linker in LeuT stability. At the higher detergent concentrations of CMCs $+0.2 \mathrm{wt} \%$, LeuT in every TSM except TSM-E9 had initial activity lower than in DDM ( $t=0$ day) but all these detergents were effective at maintaining the initial activity long term (Fig. S7 $\dagger$ ). Initial activity of LeuT was significantly enhanced with the use of the individual TEMs, again indicating that DEA is superior to serinol as a linker for LeuT stability. However, it was impossible to detect a clear preference for either alkyl chain linkage (ether $v s$ thioether). As detected at the lower detergent concentration, the most favorable efficacy for LeuT stabilization was observed for the new detergents with intermediate chain lengths (TSME8/E9/T9/T10 or TEM-E8/E9/E10/T10). A novel detergent with the shortest or longest alkyl chain (C7/C11) was generally poor in this regard, as exemplified by TSM-E7 (short), TSMT11 (long) or TEM-E11 (long). Taken together, the data indicate that the TEMs with the DEA linker were better than the serinol linker variants (TSMs) particularly at detergent concentrations of CMCs $+0.2 \mathrm{wt} \%$ and the best overall stability for LeuT was obtained with the intermediate chain lengths $(\mathrm{C} 8 / \mathrm{C} 9 / \mathrm{C} 10)$.

The new agents were further investigated for the solubilization and stabilization of melibiose permease from Salmonella typhimurium $\left(\mathrm{MelB}_{\mathrm{St}}\right) \cdot{ }^{33 \mathrm{a}-\mathrm{e}} \mathrm{MelB}_{\mathrm{St}}$ expressed in E. coli membranes was extracted on ice by each detergent, which was further treated at 45, 55, or $65^{\circ} \mathrm{C}$ for another 90 mins. Western blotting was used to quantify the amounts of soluble $\mathrm{MelB}_{\mathrm{St}}$ in the individual detergents (TEMs, TSMs and DDM). As a mild detergent minimally destroys transporter integrity at $0{ }^{\circ} \mathrm{C}$, the amount of soluble $\mathrm{MelB}_{\mathrm{St}}$ obtained at this low temperature mainly reflects detergent extraction efficiency. If detergent-extracted $\mathrm{MelB}_{\mathrm{St}}$ is thermally-treated at a high temperature of 45,55 , or $65^{\circ} \mathrm{C}$, the transporter undergoes a different degree of protein denaturation/aggregation depending on detergent effect on the thermo-stability of the transporter under the conditions. At $0{ }^{\circ} \mathrm{C}$, almost all new detergents yielded 60 80\% solubilized $\mathrm{MelB}_{\mathrm{St}}$ and were less efficient than DDM at $\mathrm{MelB}_{\mathrm{St}}$ extraction (Fig. 4 and S8 $\dagger$ ). The TEMs were more efficient than the TSMs at protein extraction, with slightly higher extraction efficiencies observed for the ether than the thioether versions. When the detergent extracted protein samples were heated to $45^{\circ} \mathrm{C}$, all TSMs yielded smaller amounts of soluble MelB ${ }_{S t}$ than DDM (Fig. S8 $\dagger$ ). In contrast, all TEMs yielded increased amounts of soluble transporter and some new detergents (TEME7/E8 and TEM-T8/T9) were comparable to DDM (Fig. 4). Interestingly, the C7/C8/C9 alkyl chain detergents (TEM-E7/E8/E9 and TEM-T7/T8/T9) yielded the large amounts of soluble $\mathrm{MelB}_{\mathrm{St}}$, indicating that these chain lengths are optimal for $\mathrm{MelB}_{\mathrm{St}}$ extraction. The limited water solubilities of the C11 alkyl chain detergents (TEM-E11 and TEM-T11) ( 1.0 wt\%) is likely responsible for their poor solubilization efficiencies observed here. The incubation of the detergent extracts at the increased temperature of $55{ }^{\circ} \mathrm{C}$ clarified difference in detergent ability to maintain protein solubility. At this high temperature, a majority of the TSMs/TEMs showed better MelB ${ }_{S t}$ solubility than DDM. Among them, the C9 alkyl chain TEMs (TEM-E9 and TEM-T9) gave the largest amounts of soluble MelB $\mathrm{St}_{\mathrm{t}}(\sim 60 \%$ and $\sim 75 \%$, respectively), in contrast to less than $5 \%$ soluble $\mathrm{MelB}_{\mathrm{St}}$ detected in DDM sample under the same conditions. This result indicates that most new detergents, especially TEME9, TEM-T9 and TEM-T8, were clearly better than DDM at preserving the soluble state of MelB $_{S t}$. Taken together, these results show that with the exception of TEM-E8, the new 
agents were less efficient at extracting $\mathrm{MelB}_{\mathrm{St}}$ from the membranes, but most of the TEMs were markedly more effective than DDM at maintaining $\mathrm{MelB}_{\mathrm{St}}$ stability. The favorable behaviors of the TEMs compared to the TSM analogs were observed in both $\mathrm{MelB}_{\mathrm{St}}$ extraction and thermo-solubility. Within each set of detergents, the $\mathrm{C} 8$ alkyl chain detergents (TEM-E8 and TSM-E8/T8) were most efficient at MelB ${ }_{\text {St }}$ extraction, while the C9 alkyl chain detergents (TEM-E9/T9 and TSM-T9) were best in retaining thermo-solubility of MelB $_{\mathrm{St}}$ in aqueous medium.

We next evaluated these new triazine-based amphiphiles with the human $\beta_{2}$ adrenergic receptor $\left(\beta_{2} \mathrm{AR}\right)$, a G-protein coupled receptor (GPCR). ${ }^{34}$ The receptor was first solubilized and purified in DDM, which was used for detergent exchange from DDM into the individual TSMs/TEMs. Ligand binding assay employing the radioactive antagonist $\left(\left[{ }^{3} \mathrm{H}\right]-\right.$ dihydroalprenolol (DHA)) was utilized to assess protein stability in the new detergents. ${ }^{35-37}$ In order to narrow down detergent molecules for further study, ligand binding activity of the receptor was initially measured following a 30-min detergent exchange (Fig. S9†). Except for the rather short alkyl chain detergents with the ether linkage (e.g., TEM-E7/E8 and TSM-E7/E8), almost every new detergent was as good as DDM at maintaining the receptor in an active state. We could not find a meaningful difference in amphiphile efficacy between the TEMs and TSMs in this evaluation, but it is interesting to note that the thioether versions were clearly better than the ether counterparts in the case of the short alkyl chain detergents. For example, TSM-T7/T8/T9 were substantially better than TSM-E7/E8/E9 at generating high receptor activity. The TEM series showed a similar trend. This result indicates that the increased hydrophobicity of the thioether versions is beneficial for $\beta_{2} A R$ stability. As TSME10/E11/T7/T8/T9 and TEM-T8/T9 showed intriguing results in the initial study, we selected these agents for long-term protein stability study. Receptor stability was monitored at regular time points over the course of incubation for 6 days at room temperature. The receptor in DDM completely lost activity in one day (Fig. 5). In contrast, all TSMs/TEMs investigated here were significantly better than DDM at keeping $\beta_{2} \mathrm{AR}$ activity, with the best performance observed for TSM-E10/T8/T9 and TEM-T8/T9. Interestingly, the optimal length of detergent alkyl chain appeared to be different depending on the alkyl chain linkage (ether/thioether). As for the ether versions, the C10 alkyl chain TSM/TEM (i.e., TSM-E10) was most capable of preserving $\beta_{2} \mathrm{AR}$ stability, whereas the $\mathrm{C} 8 / \mathrm{C} 9$ alkyl chain was optimal in the case of the thioether versions (i.e., TSM-T8/T9 and TEM-T8/T9). Detergent linker variation (serinol/DEA) had only minor effects on long-term receptor stability.

Since several new detergents (TSM-E9/E10/T8/T9 and TEM-E9/E10/T8/T9) showed a marked ability to stabilize two transporters (LeuT and MelB $\mathrm{St}_{\text {t }}$ ) and/or the GPCR $\left(\beta_{2} \mathrm{AR}\right)$, we further evaluated those detergents with the Arabidopsis thaliana boron transporter 1 (AtBOR1). This transporter belongs to the solute carrier 4 family, which was produced in Saccharomyces cerevisiae. ${ }^{38}$ AtBOR 1 stability was assessed by measuring the relative amounts of folded transporter over time during thermal denaturation at $40{ }^{\circ} \mathrm{C}$. A thiolresponsive dye, $N$-[4-(7-diethylamino-4-methyl-3-coumarinyl)phenyl] maleimide (CPM), was used to measure the extent of protein unfolding. ${ }^{39}$ When the selected TEMs and TSMs were tested at CMCs+0.04 wt\%, all agents were substantially better than DDM at preserving AtBOR1 folding state, with the best performance observed for TEM-E10 (Fig. 6a,b). A similar result was obtained from detergent evaluation at CMCs+0.2 wt\% (Fig. S10 $\dagger$ ). The 
TEMs (TEM-E9/E10/T8/T9) were further evaluated with the transporter using fluorescence size exclusion chromatography (FSEC). We first extracted the transporter-GFP fusion protein using $1.0 \mathrm{wt} \%$ of individual detergents at $25{ }^{\circ} \mathrm{C}$. DDM extracted $\sim 80 \%$ transporter from the membrane while the use of the TEMs resulted in $\sim 60 \%$ solubilization. The exception was TEM-T9 which extracted $\sim 45 \%$. This result is more or less consistent with the $\mathrm{MelB}_{\mathrm{St}}$ solubilization result (Fig. 4). The detergent-extracted transporter was incubated at $47{ }^{\circ} \mathrm{C}$ for $10 \mathrm{~min}$ and the integrity of the thermally treated protein was then assessed using FSEC. The DDM-solubilized transporter showed a significant reduction in the mondisperse protein peak (fraction number 35), along with a large increase in the aggregation peak (fraction number 2) (Fig. 6c). In contrast, all tested TEMs were highly effective at maintaining integrity of the transporter under the same conditions (Fig. 6c, d). A minimal amount of protein aggregation was observed when the transporter was solubilized in the new detergents. This result indicates that the novel detergents, although a little less efficient at protein extraction, were superior to DDM at stabilizing AtBOR1.

The selected detergents (TSM-E9/E10/T8/T9 and TEM-E9/E10/T8/T9) were further evaluated with the mouse $\mu$-opioid receptor (MOR), another GPCR. ${ }^{40}$ Detergent exchange was conducted using the DDM/CHS-purified receptor via dilution method. At a detergent concentration of $0.5 \mathrm{wt} \%, \mathrm{CPM}$ assay was carried out to estimate melting temperature $\left(T_{\mathrm{m}}\right)$ of the receptor which was utilized to assess receptor stability. ${ }^{39}$ The control sample was DDM-solubilized receptor which was tested without detergent exchange as this resulted in partial receptor denaturation. MOR in DDM/CHS yielded a relatively low $T_{\mathrm{m}}$ value (31.6 ${ }^{\circ} \mathrm{C}$ ) (Fig. 7). In contrast, all tested TSM/TEMs resulted in higher receptor $T_{\mathrm{m}} \mathrm{s}$. TEM-T8, the least effective of the tested new detergents, gave a receptor $T_{\mathrm{m}}$ of $35.9{ }^{\circ} \mathrm{C}, 4.3^{\circ} \mathrm{C}$ higher than DDM. TEM-E10 and TSM-E10 yielded $T_{\mathrm{m}} \mathrm{s}$ of the receptor of 48.0 and $48.9^{\circ} \mathrm{C}$, respectively (Table S1). TEM-E10 and TSM-E10 also gave higher $T_{m}$ than LMNG $\left(38.3^{\circ} \mathrm{C}\right)$ which has contributed to structure determination of a number of novel GPCRs including the receptor. ${ }^{41}$

Because of favorable behaviors with all membrane proteins tested here, a few TEMs (TEME9/E10/T8/T9) were selected for further evaluation. First, these new detergents were used to extract a GPCR ( $\beta_{2} \mathrm{AR}$ or MOR) from the membrane. The amounts of solubilized receptors were estimated using SDS-PAGE and Western blot analysis. As for $\beta_{2}$ AR extraction, the TEM-Es (TEM-E9 and TEM-E10) were as efficient as DDM while the TEM-Ts (TEM-T8 and TEM-T9) were slightly worse than DDM (Fig. S11a). A similar result was observed for MOR (Fig. S11b). When the detergent-extracted $\beta_{2} \mathrm{AR}$ was used for $\left[{ }^{3} \mathrm{H}\right]-\mathrm{DHA}$ binding assay, TEM-T8 and TEM-T9 were better than DDM whereas TEM-E10 was comparable to DDM (Fig. S12a). In the case of MOR, all tested detergents yielded enhanced ligand binding ability of the receptor compared to DDM (Fig. S12b). Second, the selected TEMs were further evaluated with regards to protein stabilization efficacy, particularly for comparison with the previously developed novel detergents (OGNG and LMNG). The stability of each protein (LeuT or $\beta_{2} \mathrm{AR}$ ) was assessed using the same protocol described above (i.e., substrate/ligand binding activity). As for long-term stability of LeuT, the three detergents (TEM-E9/T8/T9) were more or less comparable to LMNG, but TEM-E10 was clearly better than this NG detergent (Fig. S13). When evaluated with $\beta_{2}$ AR, TEM-E9 and TEM-T8 were worse than LMNG at stabilizing the receptor, while TEM-E10 was comparable to the latter. Intriguingly, TEM-T9 was markedly more effective than LMNG at stabilizing the receptor 
long term. OGNG was ineffective at stabilizing both membrane proteins (LeuT and $\beta_{2} \mathrm{AR}$ ), consistent with a previous result. ${ }^{18 a}$ Combined with the results obtained for MOR, two TEMs (TEM-T9 and TEM-E10) are the best amphiphiles and notably superior to LMNG at stabilizing both GPCRs. As LMNG is a significantly improved novel detergent for GPCR stability, this result indicates that these TEMs hold promising potential for GPCR structural study.

\section{Discussion}

We developed a novel class of 1,3,5-triazine-cored amphiphiles with a branched dimaltoside and two alkyl chains. These novel detergents were evaluated with several model membrane protein systems (LeuT, MelB ${ }_{S t}, \beta_{2} \mathrm{AR}$, AtBOR1 and MOR) using various methodologies for evaluation of protein stability including CPM assays and ligand binding assays.

Encouragingly, most TSMs and TEMs were notably more effective than a gold standard classical detergent (DDM) at stabilizing the tested membrane proteins long term, indicating that these detergents contain a favorable architecture for enhanced membrane protein stability. Each membrane protein requires distinct detergent property for optimal protein stability and thus we observed protein-specific nature of detergent efficacy in the current study. As for LeuT stability, TSM-E8/E9 and TEM-E10/T10 were the best agents, while TEM-T8/T9 was optimal for MelB ${ }_{\mathrm{St}}$ stability. When tested with $\beta_{2} \mathrm{AR}$ and AtBOR1, the best behaviors were observed for TSM-E10 and TEM-T9 $\left(\beta_{2} \mathrm{AR}\right)$ and TEM-E10 (AtBOR1). TSM-E10 and TEM-E10 were also the best agents for MOR stability. This is consistent with the general notion that individual membrane proteins require different detergent properties for optimal stability due to their differing physical properties and three-dimensional structures, and thus there is unlikely to be a single detergent that is optimal for many membrane proteins. Despite the preference of the individual membrane proteins for a particular detergent, some new detergents seemed universally effective at membrane protein stability. For instance, TEM-E10 and TEM-T9 were markedly superior to DDM for all the tested membrane proteins. These detergents were even substantially more effective than the significantly optimized novel detergent, LMNG, at stabilizing two GPCRs ( $\beta_{2} \mathrm{AR}$ and MOR) and LeuT. This result indicates that these detergents are particularly useful for GPCR structural study. Although TSM-E10 and TSM-T9 were only slightly better than DDM for $\mathrm{MelB}_{\mathrm{St}}$ stability, these TSM agents were clearly superior to the conventional detergent for stability of the other membrane proteins (LeuT, $\beta_{2} \mathrm{AR}$, AtBOR1 and MOR). On the other hand, TEM-E9 was notably effective for all the tested membrane proteins except $\beta_{2} \mathrm{AR}$. Thus, these new amphiphiles (TSM-E10, TSM-T9, and TEM-E9) also hold potential for membrane protein structural study.

This study varied both the alkyl chain linkage (ether/thioether) and linker identity (serinol/ DEA), allowing us to investigate the effects of these structural differences on membrane protein stability in detail. In previous studies, an ether linkage has been compared with an alkyl linkage, ${ }^{14,16,42}$ but it is unusual to compare the thioether linkage with another (ether or alkyl) in the context of novel detergent structure. Due to the high hydrophobicity of the sulfur atom ( $v S$ oxygen) and relatively long $\mathrm{C}-\mathrm{S}$ bond ( $v S \mathrm{C}-\mathrm{O}$ ), the thioether linkage-bearing detergents gave lower CMCs and larger micelle sizes than the ether counterparts, respectively (Table 1). As detergent hydrophobicity and hydrophobic group length are 
important for protein stability, this variation in the alkyl chain linkage affects detergent efficacy for membrane protein manipulation. The thioether versions (TSM-Ts and TEM-Ts) were overall less efficient than the ether counterparts at extracting $\beta_{2} \mathrm{AR}, \mathrm{MelB}_{\mathrm{St}}$ and MOR. However, the sulfur-linked detergents were clearly better than the ether counterparts at maintaining both MelB ${ }_{S t}$ and $\beta_{2} \mathrm{AR}$ stability. In the case of the other membrane proteins (LeuT, AtBOR1 and MOR), it was hard to find a clear difference in detergent efficacy for protein stabilization as the best agent of one set was similarly effective to that of the other set at stabilizing those membrane proteins. However, we found a clear variation in the optimal alkyl chain length for protein stability between these two versions (ether/thioether), mainly originating from differences in the hydrophobicity of the $\mathrm{C}-\mathrm{S}$ and $\mathrm{C}-\mathrm{O}$ bonds. The optimal alkyl chain length for LeuT stability was in the range of $\mathrm{C} 8$ to $\mathrm{C} 11$ for the ether versions, while the shorter alkyl chains (C7 to $\mathrm{C} 10)$ were optimal for the thioether versions. A more dramatic difference was found in $\beta_{2} A R$ study where the optimal alkyl chain lengths were found at $\mathrm{C} 10$ and $\mathrm{C} 9$ for the ether and thioether versions, respectively. As the C-S bond is longer and more hydrophobic than the $\mathrm{C}-\mathrm{O}$ bond, the optimal detergent property seems to have been achieved by a shorter alkyl chain for the thioether versions. The favorable role of the thioether linkage was additionally observed for the shortest alkyl chain (C7) detergents; the thioether detergents containing the C7 alkyl chain (i.e., TSM-T7 and TEM-T7) were among the best agents for LeuT stability, while their ether counterparts (i.e., TSM-E7 and TEM-E7) were the worst agents. In the case of $\beta_{2} \mathrm{AR}$ stability, the thioether versions with a short alkyl chain (C7/C8) were clearly better than the ether counterparts (e.g., TSM-T7/T8 vs TSM-E7/E8).

Detergent efficacy for protein stabilization was also affected by which linker, serinol or DEA, was used to connect the maltoside headgroup to the 1,3,5-triazine ring. The TEMs and TSMs were broadly comparable in terms of stabilizing $\beta_{2} \mathrm{AR}$ and AtBOR 1 . However, the detergents with the DEA linker (i.e., TEMs) were more effective than the TSMs at stabilizing LeuT and both extracting and stabilizing $\mathrm{MelB}_{\mathrm{St}}$. It is hard to be clear regarding which feature of the DEA linker is responsible for the superior detergent efficacy observed for those membrane proteins. However, this could, at least in part, be related to the enhanced micellar stability of the TEMs compared to the TSM analogs, which is supported by their lower CMCs than the serinol-linked detergents (Table 1). It is important to note that detergent efficacy for protein stabilization is determined by multiple factors including HLB, hydrophobic length, micelle size and hydrophobic density. ${ }^{43}$ Based on the marked protein stabilization efficacy observed here, the 1,3,5-triazine-cored detergents introduced here are likely to be optimal in terms of several of these factors, something that is challenging to achieve in a single chemical architecture.

The 1,3,5-triazine scaffold used as the detergent core structure in the current study has clear merit as it provides large structural diversity and synthetic convenience. This detergent property is important as it facilitates detergent optimization and allows widespread use of the new detergent tools. Cyanuric chloride, the inexpensive starting material used for detergent synthesis, can react with various nucleophiles. In this work, we used alkanol/alkanethiol as a hydrophobic group, and an amine-functionalized diol (serinol and DEA) as a linker. Thanks to the high reactivity of cyanuric chloride, many structurally diverse nucleophiles including sterically hindered ones ${ }^{44}$ and $\beta$-branched alkanol ${ }^{45}$ could be easily introduced as 
alternatives to the current alkyl groups. In addition, any lengthy derivatizations of the functional groups are unnecessary, which allowed us to prepare the glycosylation substrates (i.e., the diol derivatives) in just two efficient steps. Thus, we can substantially and conveniently increase the structural diversity of this class, allowing scope for further optimization. More importantly, the reactivity of cyanuric chloride with a nucleophile is modulated by varying the substituent numbers around the ring. Specifically, reactivity of these aromatic chlorides substantially decreases with increasing number of ring substituents (less electrophilic), due to a large change in the electronic configuration of the ring. Thus, a selective mono- or di-substitution can be readily attained by simply controlling reaction conditions. In this study, we introduced the same alkyl chain (RO- or RS-) into the core ring as the hydrophobic groups , and thus these are classified as symmetric detergents. ${ }^{9 \mathrm{f}}$ Thanks to the high selectivity in the mono-substitution, however, the two different hydrophobic groups can be conveniently conjugated to the central ring to yield asymmetric detergent molecules. ${ }^{9 f}$ The new detergents (TEM-E10 and TEM-T9) introduced here showed markedly increased protein stabilization efficacy with a few tested membrane proteins compared to a standard detergent (DDM) and an optimized novel detergent (LMNG), yet there is scope for further optimization.

\section{Conclusions}

We report herein two sets of 1,3,5-triazine-cored maltosides (TSMs and TEMs) that vary in the alkyl chain linkage (ether/thioether) and linker identity (serinol/DEA). Of the 20 new agents, we identified two new detergents (i.e., TEM-E10 and TEM-T9) which are appreciably more effective than a gold standard conventional detergent (DDM) and an optimized novel detergent (LMNG) at stabilizing a range of membrane proteins, including two GPCRs. Due to the synthetic accessibility and diversity as well as the marked protein stabilization, the new detergents introduced here have the potential for wide use in membrane protein structural study. Furthermore, the fact that convenient modification of the detergent structure is possible will allow us to generate detergents with improved efficacy or customizable properties. In addition, the relationships between detergent structure and efficacy for protein stabilization discussed here will further enrich the repertoire of detergent tools for membrane protein research.

\section{Supplementary Material}

Refer to Web version on PubMed Central for supplementary material.

\section{Acknowledgements}

This work was supported by the National Research Foundation of Korea (NRF) (2016R1A2B2011257 and 2018R1A6A1A03024231 to P.S.C.) and by the National Institutes of Health (grants R21NS105863 and R01GM122759 to L.G.). S.K. is the recipient of the Japan Society for the Promotion of Science Postdoctoral Fellowship Award. The European Union's Horizon 2020 research and innovation programme, RAMP-ITN: Rationalising Membrane Protein Crystallisation Innovative Training Network, under the Marie Sklodowska-Curie grant agreement No 722687 (CC) funded this work, also supported by BBSRC grant BB/N016467/1 awarded to BB. 


\section{REFERENCES}

1. Overington JP; Al-Lazikani B; Hopkins AL How many drug targets are there. Nat. Rev. Drug discovery 2006, 5, 993-996. [PubMed: 17139284]

2. Deisenhofer J; Epp O; Miki K; Huber R; Michel H Structure of the protein subunits in the photosynthetic reaction centre of Rhodopseudomonas viridis at $3 \AA$ resolution. Nature 1985, 318, 618-624. [PubMed: 22439175]

3. (a)https://www.rcsb.org/.(b)https://www.wwpdb.org/.

4. (a)Garavito RM; Ferguson-Miller S Detergents as tools in membrane biochemistry. J. Biol. Chem, 2001, 276, 32403-32406. [PubMed: 11432878] (b)Serrano-Vega MJ, Magnani F, Shibata Y, Tate CG Conformational thermostabilization of the $\beta 1$-adrenergic receptor in a detergent-resistant form. Proc. Natl. Acad. Sci., U. S. A, 2008, 105, 877-882. [PubMed: 18192400]

5. (a)Ewstead S; Ferrandon S; Iwata S Rationalizing a-helical membrane protein crystallization. Protein Science, 2008, 17, 466-472. [PubMed: 18218713] (b)He Y, Wang K, \& Yan N The recombinant expression systems for structure determination of eukaryotic membrane proteins. Protein \& cell, 2014, 5, 658-672. [PubMed: 25119489] (c)Parker JL, \& Newstead S Current trends in a-helical membrane protein crystallization: an update. Protein Science, 2012, 21, 1358-1365. [PubMed: 22811290]

6. (a)Chae PS; Wander MJ; Cho KH; Laible PD; Gellman SH Carbohydrate-containing Triton X-100 analogues for membrane protein solubilization and stabilization. Molecular BioSystems, 2013, 9 , 626-629. [PubMed: 23377371] (b)Bae HE, Gotfryd K, Thomas J, Hussain H, Ehsan M, Go J Chae PS. Deoxycholate-Based Glycosides (DCGs) for Membrane Protein Stabilisation. ChemBioChem, 2015, 16, 1454-1459. [PubMed: 25953685]

7. (a)Nath A, Atkins WM, Sligar SG Applications of phospholipid bilayer nanodiscs in the study of membranes and membrane proteins. Biochemistry, 2007, 46, 2059-2069. [PubMed: 17263563] (b)Tribet C; Audebert R; Popot J-L Amphipols: polymers that keep membrane proteins soluble in aqueous solutions. Proc. Natl. Acad. Sci. U.S.A, 1996, 93, 15047-15050. [PubMed: 8986761] (c)Popot JL, Althoff T, Bagnard D, Banères JL, Bazzacco P, Billon-Denis E, \& Crémel G Amphipols from A to Z. Annu. Rev. Biophys, 2011, 40, 379-408. [PubMed: 21545287] (d)OrwickRydmark M, Lovett JE, Graziadei A, Lindholm L, Hicks MR, Watts A Detergent-free incorporation of a seven-transmembrane receptor protein into nanosized bilayer Lipodisq particles for functional and biophysical studies. Nano letters, 2012, 12, 4687-4692. [PubMed: 22827450] (e)Broecker J; Eger BT; Ernst OP Crystallogenesis of membrane proteins mediated by polymer-bounded lipid nanodiscs. Structure 2017, 25, 384-392. [PubMed: 28089451]

8. (a)McGregor C-L; Chen L; Pomroy NC; Hwang P; Go S; Chakrabartty A; Privé GG Lipopeptide detergents designed for the structural study of membrane proteins. Nature biotechnology, 2003, 21, 171.(b)Tao H, Lee SC, Moeller A, Roy RS, Siu FY, Zimmermann J, Zhang Q Engineered nanostructured $\beta$-sheet peptides protect membrane proteins. Nature methods, 2013, 10, 759. [PubMed: 23817067]

9. (a)Chae PS; Rasmussen SG; Rana RR; Gotfryd K; Chandra R; Goren MA; Kruse AC; Nurva S; Loland CJ; Pierre Y Maltose-neopentyl glycol (MNG) amphiphiles for solubilization, stabilization and crystallization of membrane proteins. Nature methods, 2010, 7, 1003. [PubMed: 21037590] (b)Chae PS, Rana RR, Gotfryd K, Rasmussen SG, Kruse AC, Cho KH, \& Gether U Glucoseneopentyl glycol (GNG) amphiphiles for membrane protein study. Chem. Commun, 2013 49, 22872289.(c)Cho KH, Husri M, Amin A, Gotfryd K, Lee HJ, Go J, \& Chae PS Maltose neopentyl glycol-3 (MNG-3) analogues for membrane protein study. Analyst, 2015, 140, 3157-3163. [PubMed: 25813698] (d)Sadaf A, Mortensen JS, Capaldi S, Tikhonova E, Hariharan P, Ribeiro O, \& Chae PS A class of rigid linker-bearing glucosides for membrane protein structural study. Chem. Sci, 2016, 7, 1933-1939. [PubMed: 27110345] (e)Bae HE, Du Y, Hariharan P, Mortensen JS, Kumar KK, Ha B, \& Kobilka BK Asymmetric maltose neopentyl glycol amphiphiles for a membrane protein study: effect of detergent asymmetricity on protein stability. Chem. Sci, 2019, 10, 1107-1116. [PubMed: 30774908]

10. Frotscher E; Danielczak B; Vargas C; Meister A; Durand G; Keller S A Fluorinated detergent for membrane protein applications. Angew. Chem., Int. Ed, 2015, 54, 5069-5073. 
11. (a)Chae PS; Gotfryd K; Pacyna J; Miercke LJ; Rasmussen SG; Robbins RA; Rana RR; Loland CJ; Kobilka B; Stroud R Tandem facial amphiphiles for membrane protein stabilization. J. Am. Chem. Soc, 2010, 132, 16750-16752. [PubMed: 21049926] (b)Lee SC, Bennett BC, Hong WX, Fu Y, Baker KA, Marcoux J, Stout CD Steroid-based facial amphiphiles for stabilization and crystallization of membrane proteins. Proc. Natl. Acad. Sci. USA, 2013, 110, E1203-E1211. [PubMed: 23479627]

12. Chae PS; Kruse AC; Gotfryd K; Rana RR; Cho KH; Rasmussen SG; Bae HE; Chandra R; Gether U; Guan L Novel tripod amphiphiles for membrane protein analysis. Chem. Eur. J, 2013, 19, 15645-15651. [PubMed: 24123610]

13. Hussain H; Du Y; Scull NJ; Mortensen JS; Tarrasch J; Bae HE; Loland CJ; Byrne B; Kobilka BK; Chae PS Accessible Mannitol-Based Amphiphiles (MNAs) for Membrane Protein Solubilisation and Stabilisation. Chem. Eur. J, 2016, 22 , 7068-7073. [PubMed: 27072057]

14. (a)Cho KH; Du Y; Scull NJ; Hariharan P; Gotfryd K; Loland CJ; Guan L; Byrne B; Kobilka BK; Chae PS Novel Xylene-Linked Maltoside Amphiphiles (XMAs) for Membrane Protein Stabilisation. Chem. Eur. J, 2015, 21, 10008-10013. [PubMed: 26013293] (b)Cho KH, Ribeiro O, Du Y, Tikhonova E, Mortensen JS, Markham K, \& Byrne B Mesitylene-Cored Glucoside Amphiphiles (MGAs) for Membrane Protein Studies: Importance of Alkyl Chain Density in Detergent Efficacy. Chem. Eur. J, 2016, 22, 18833-18839. [PubMed: 27743406]

15. Ehsan M; Du Y; Scull NJ; Tikhonova E; Tarrasch J; Mortensen JS; Loland CJ; Skiniotis G; Guan L; Byrne B Highly branched pentasaccharide-bearing amphiphiles for membrane protein studies. J. Am. Chem. Soc, 2016, 138 , 3789-3796. [PubMed: 26966956]

16. (a)Das M; Du Y; Mortensen JS; Ribeiro O; Hariharan P; Guan L; Loland CJ; Kobilka BK; Byrne B; Chae PS Butane-1, 2, 3, 4-tetraol-based amphiphilic stereoisomers for membrane protein study: importance of chirality in the linker region. Chem. Sci, 2017, 8, 1169-1177; [PubMed: 28451257] (b)Das M, Du Y, Ribeiro O, Hariharan P, Mortensen JS, Patra D, \& Byrne B Conformationally preorganized diastereomeric norbornane-based maltosides for membrane protein study: Implications of detergent kink for micellar properties. J. Am. Chem. Soc, 2017, 139, 3072-3081. [PubMed: 28218862]

17. Sadaf A; Du Y; Santillan C; Mortensen J; Molist I; Seven A; Hariharan P; Skiniotis G; Loland C, Kobilka BK; Guan L; Byrne B; Chae PS Dendronic trimaltose amphiphiles (DTMs) for membrane protein study. Chem. Sci, 2017, 8, 8315-8324. [PubMed: 29619178]

18. (a)Chae PS; Rana RR; Gotfryd K; Rasmussen SG; Kruse AC; Cho KH; Capaldi S; Carlsson E; Kobilka B; Loland CJ Glucose-neopentyl glycol (GNG) amphiphiles for membrane protein study. Chem. Commun, 2013, 49, 2287-2289.(b)Kellosalo J, Kajander T, Kogan K, Pokharel K, \& Goldman A The structure and catalytic cycle of a sodium-pumping pyrophosphatase. Science, 2012, 337, 473-476. [PubMed: 22837527] (c)Frick A, Eriksson UK, De Mattia F, Öberg F, Hedfalk K, Neutze R, Törnroth-Horsefield S X-ray structure of human aquaporin 2 and its implications for nephrogenic diabetes insipidus and trafficking. Proc. Natl. Acad. Sci. USA, 2014, 111, 6305-6310. [PubMed: 24733887]

19. (a)Hauer F, Gerle C, Fischer N, Oshima A, Shinzawa-Itoh K, Shimada S, \& Stark H GraDeR: membrane protein complex preparation for single-particle cryo-EM. Structure, 2015, 23, 17691775. [PubMed: 26278176] (b)Yin J, Mobarec JC, Kolb P, Rosenbaum DM Crystal structure of the human OX 2 orexin receptor bound to the insomnia drug suvorexant. Nature, 2015, 519, 247-250. [PubMed: 25533960] (c)Kang Y, Zhou XE, Gao X, He Y, Liu W, Ishchenko A, \& Xu Q Crystal structure of rhodopsin bound to arrestin by femtosecond X-ray laser. Nature, 2015, 523, 561-567. [PubMed: 26200343] (d)Perez C, Gerber S, Boilevin J, Bucher M, Darbre T, Aebi M, \& Locher KP Structure and mechanism of an active lipid-linked oligosaccharide flippase. Nature, 2015, 524, 433-438. [PubMed: 26266984] (e)Dong YY, Pike AC, Mackenzie A, McClenaghan C, Aryal P, Dong L, \& Ruda GF K2P channel gating mechanisms revealed by structures of TREK-2 and a complex with Prozac. Science, 2015, 347,1256-1259. [PubMed: 25766236] (f)Paulsen CE, Armache JP, Gao Y, Cheng Y, \& Julius D Structure of the TRPA1 ion channel suggests regulatory mechanisms. Nature, 2015, 520, 511-517. [PubMed: 25855297] (g)Schmidt HR, Zheng S, Gurpinar E, Koehl A, Manglik A, Kruse AC. Crystal structure of the human $\sigma 1$ receptor. Nature, 2016, 532, 527-530. [PubMed: 27042935] 
20. Menicagli R; Samaritani S; Signore G; Vaglini F; Dalla Via L In vitro cytotoxic activities of 2alkyl-4, 6-diheteroalkyl-1,3,5-triazines: new molecules in anticancer research. J. med.chem, 2004, 47, 4649-4652. [PubMed: 15341480]

21. Moon H-S; Jacobson EM; Khersonsky SM; Luzung MR; Walsh DP; Xiong W; Lee JW; Parikh PB; Lam JC; Kang T-W A novel microtubule destabilizing entity from orthogonal synthesis of triazine library and zebrafish embryo screening. J. Am. Chem. Soc, 2002, 124, 11608-11609. [PubMed: 12296721]

22. Arya K; Dandia A Synthesis and cytotoxic activity of trisubstituted-1, 3, 5-triazines. Bioorg. Med. Chem. Lett, 2007, 17, 3298-3304. [PubMed: 17449247]

23. Zhou C; Min J; Liu Z; Young A; Deshazer H; Gao T; Chang Y-T; Kallenbach NR Synthesis and biological evaluation of novel 1, 3, 5-triazine derivatives as antimicrobial agents. Bioorg. Med. Chem. Lett, 2008, 18, 1308-1311. [PubMed: 18226902]

24. Srinivas K; Srinivas U; Bhanuprakash K; Harakishore K; Murthy U; Rao VJ Synthesis and antibacterial activity of various substituted s-triazines. Eur. J. Med. Chem, 2006, 41, 1240-1246. [PubMed: 16815597]

25. Xiong Y-Z; Chen F-E; Balzarini J; De Clercq E; Pannecouque C Non-nucleoside HIV-1 reverse transcriptase inhibitors. Part 11: structural modulations of diaryltriazines with potent anti-HIV activity. Eur. J. Med. Chem, 2008, 43, 1230-1236. [PubMed: 17869386]

26. Yang K; Xu M-J; Li B Synthesis of N-ethyl triazine-piperazine copolymer and flame retardancy and water resistance of intumescent flame retardant polypropylene. Polymer Degrad. and Stability, 2013, 98, 1397-1406.

27. Ehsan M; Du Y; Molist I; Seven AB; Hariharan P; Mortensen JS; Ghani L; Loland CJ; Skiniotis G; Guan L Vitamin E-based glycoside amphiphiles for membrane protein structural studies. Org. Biomol. Chem, 2018, 16, 2489-2498. [PubMed: 29564464]

28. Asada A; Sonoyama M, Solubilization and structural stability of bacteriorhodopsin with a mild nonionic detergent, n-octyl- $\beta$-dthioglucoside, Biosc. Biotechnol. Biochem, 2011, 75, 376-378.

29. Chattopadhyay A; London E Fluorimetric determination of critical micelle concentration avoiding interference from detergent charge. Anal. Biochem, 1984, 139, 408-412. [PubMed: 6476378]

30. Plum MA; Steffen W; Fytas G; Knoll W; Menges B Probing dynamics at interfaces: resonance enhanced dynamic light scattering. Optics express, 2009, 17, 10364-10371. [PubMed: 19506690]

31. Deckert G; Warren PV; Gaasterland T; Young WG; Lenox AL; Graham DE; Overbeek R; Snead MA; Keller M; Aujay M The complete genome of the hyperthermophilic bacterium Aquifex aeolicus. Nature, 1998, 392, 353-358. [PubMed: 9537320]

32. Quick M; Javitch JA Monitoring the function of membrane transport proteins in detergentsolubilized form. Proc. Natl. Acad. Sci. U. S. A, 2007, 104, 3603-3608. [PubMed: 17360689]

33. (a)Guan L; Nurva S; Ankeshwarapu SP Mechanism of melibiose/cation symport of the melibiose permease of Salmonella typhimurium. J. Biol. Chem, 2011, 286, 6367-6374. [PubMed: 21148559] (b)Ethayathulla AS, Yousef MS, Amin A, Leblanc G, Kaback HR, \& Guan L Structure-based mechanism for Na+/melibiose symport by MelB. Nat. Commun, 2014, 5, 3009;(c)Amin A, Ethayathulla AS, \& Guan L Suppression of conformation-compromised mutants of Salmonella enterica serovar Typhimurium MelB. J. Bacteriol, 2014, 196, 3134-3139; [PubMed: 24957620] (d)Amin A, Hariharan P, Chae PS, \& Guan L Effect of detergents on galactoside binding by Melibiose permeases. Biochemistry, 2015, 54, 5849-5855; [PubMed: 26352464] (e)Cordat E, Mus-Veteau I, Leblanc G Structural Studies of the Melibiose Permease of Escherichia coli by Fluorescence Resonance Energy Transfer II. Identification of the tryptophan residues acting as energy donors. J. Biol. Chem, 1998, 273, 33198-33202. [PubMed: 9837888]

34. Rosenbaum DM, Cherezov V, Hanson MA, Rasmussen SG, Thian FS, Kobilka TS, \& Kobilka BK GPCR engineering yields high-resolution structural insights into $\beta 2$-adrenergic receptor function. Science, 2007, 318, 1266-1273. [PubMed: 17962519]

35. Mansoor SE; Mchaourab HS; Farrens DL Mapping proximity within proteins using fluorescence spectroscopy. A study of T4 lysozyme showing that tryptophan residues quench bimane fluorescence. Biochemistry, 2002, 41, 2475-2484. [PubMed: 11851393] 
36. Yao X; Parnot C; Deupi X; Ratnala VR; Swaminath G; Farrens D; Kobilka B Coupling ligand structure to specific conformational switches in the $\beta$ 2-adrenoceptor. Nat. Chem. Biol, 2006, 2 , 417-422. [PubMed: 16799554]

37. waminath G; Steenhuis J; Kobilka B; Lee TW Allosteric modulation of $\beta 2$-adrenergic receptor by Zn2+. Mol. Pharmacol, 2002, 61, 65-72. [PubMed: 11752207]

38. Thurtle-Schmidt BH; Stroud RM Structure of Bor1 supports an elevator transport mechanism for SLC4 anion exchangers. Proc. Natl. Acad. Sci. U.S.A, 2016, 113, 10542-10546. [PubMed: 27601653]

39. Hanson MA, Cherezov V, Griffith MT, Roth CB, Jaakola VP, Chien EY, Stevens RC A specific cholesterol binding site is established by the $2.8 \AA$ structure of the human $\beta 2$-adrenergic receptor. Structure, 2008, 16, 897-905. [PubMed: 18547522]

40. Manglik A; Kruse AC; Kobilka TS; Thian FS; Mathiesen JM; Sunahara RK; Pardo L; Weis WI; Kobilka BK; Granier S Crystal structure of the $\mu$-opioid receptor bound to a morphinan antagonist. Nature, 2012, 485, 321. [PubMed: 22437502]

41. Huang W; Manglik A; Venkatakrishnan A; Laeremans T; Feinberg EN; Sanborn AL; Kato HE; Livingston KE; Thorsen TS; Kling RC Structural insights into $\mu$-opioid receptor activation. Nature, 2015, 524, 315-321. [PubMed: 26245379]

42. Ehsan M; Ghani L; Du Y; Hariharan P; Mortensen JS; Ribeiro O; Hu H; Skiniotis G; Loland CJ; Guan L New penta-saccharide-bearing tripod amphiphiles for membrane protein structure studies. Analyst, 2017, 142, 3889-3898. [PubMed: 28913526]

43. (a)Cho KH; Hariharan P; Mortensen JS; Du Y; Nielsen AK; Byrne B; Kobilka BK; Loland CJ; Guan L; Chae PS Isomeric Detergent Comparison for Membrane Protein Stability: Importance of Inter-Alkyl-Chain Distance and Alkyl Chain Length. ChemBioChem, 2016, 17, 2334-2339. [PubMed: 27981750] (b)Das M, Du Y, Mortensen JS, Ramos M, Ghani L, Lee HJ, \& Kobilka BK Trehalose-cored amphiphiles for membrane protein stabilization: importance of the detergent micelle size in GPCR stability. Org. Biomol. Chem, 2019,17, 3249-3257. [PubMed: 30843907]

44. Chae PS; Bae HE; Das M Adamantane-based amphiphiles (ADAs) for membrane protein study: importance of a detergent hydrophobic group in membrane protein solubilisation. Chem. Commun, 2014, 50, 12300-12303.

45. Hussain H; Helton T; Du Y; Mortensen JS; Hariharan P; Ehsan M; Byrne B; Loland CJ; Kobilka BK; Guan L A comparative study of branched and linear mannitol-based amphiphiles on membrane protein stability. Analyst, 2018, 143, 5702-5710. [PubMed: 30334564] 
<smiles>CCCCCCCCOC(O)C(O)C(O)C1(O)COCC1(O)CO</smiles>

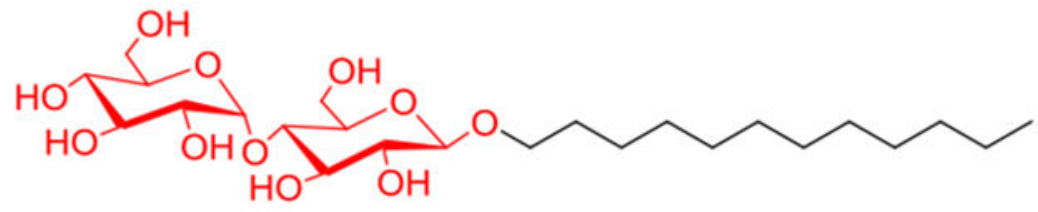

OG

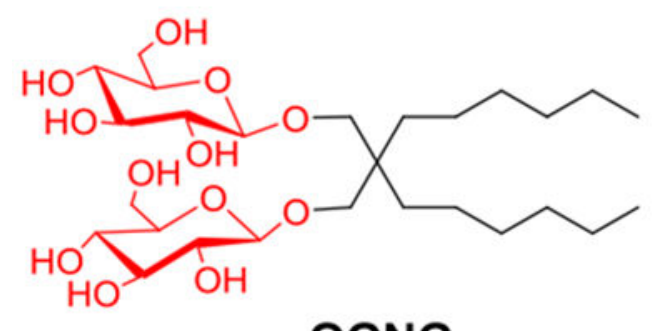

OGNG

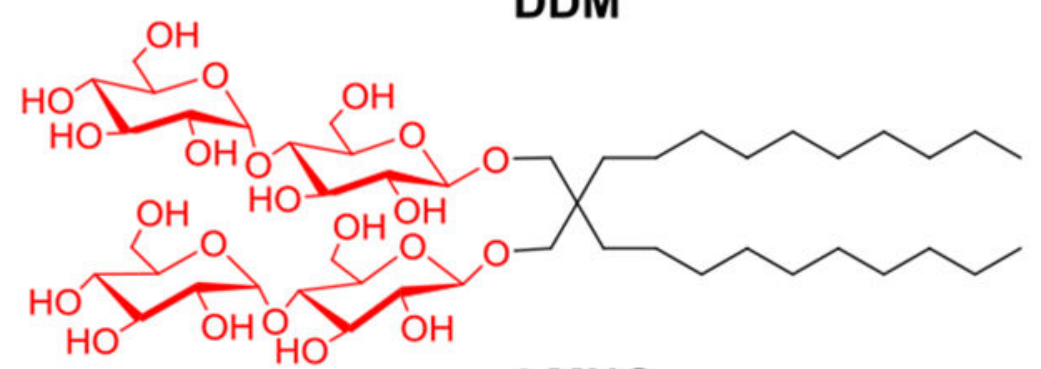

LMNG

Fig. 1.

Chemical structures of conventional detergents (OG and DDM) and the recently developed NG class detergents (OGNG and LMNG). These detergents are most widely used for membrane protein study. 
a
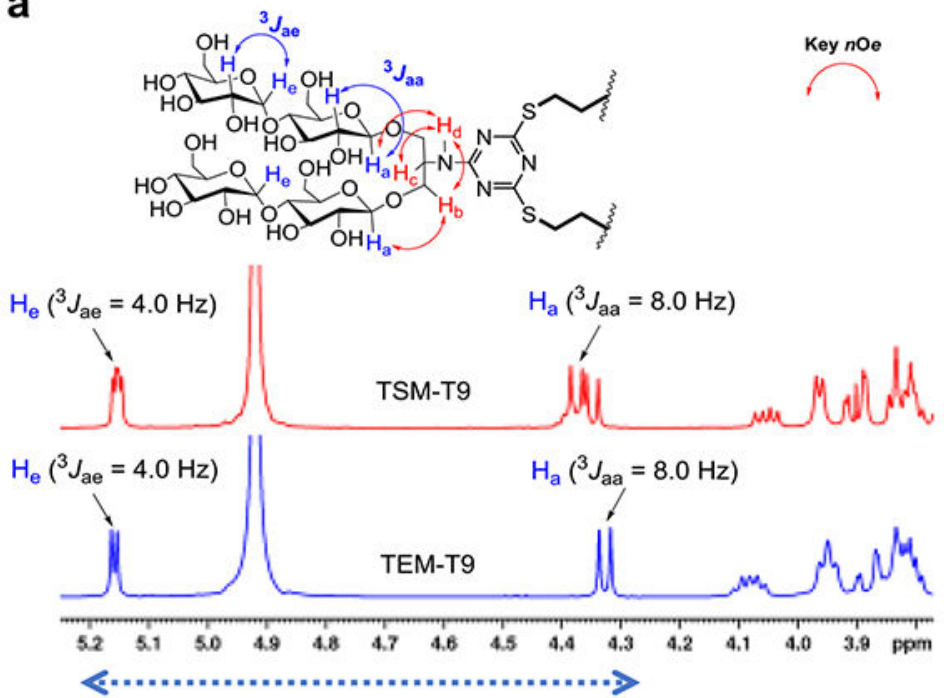

Anomeric region

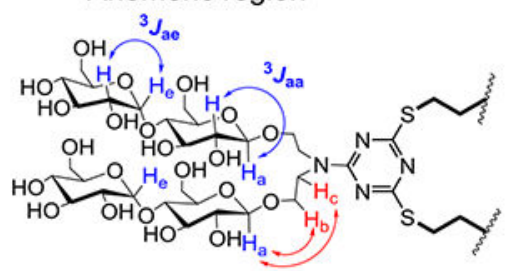

b
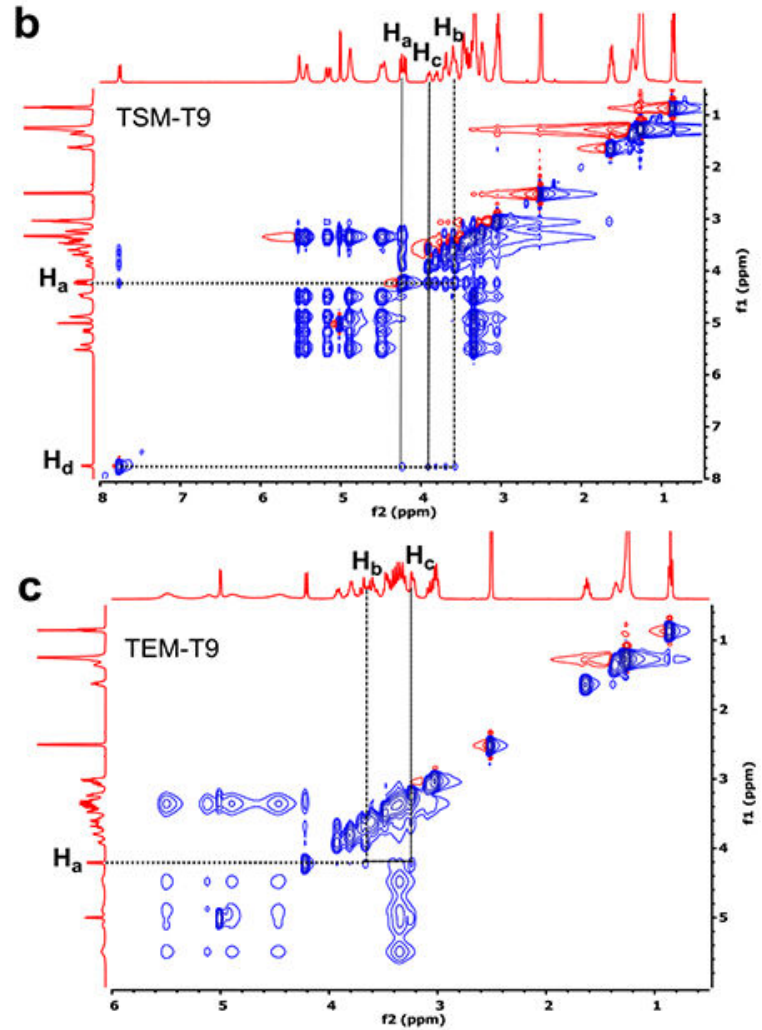

Fig. 2.

(a) Partial ${ }^{1} \mathrm{H}$ NMR spectra of TSM-T9 and TEM-T9 in $\mathrm{CD}_{3} \mathrm{OD}$ in the anomeric regions.

Two kinds of anomeric protons $\left(\mathrm{H}_{\mathrm{a}}\right.$ and $\left.\mathrm{H}_{\mathrm{e}}\right)$ and their neighboring protons $(\mathrm{H})$ are illustrated in the detergent chemical structures. The spectrum of TSM-T9 gave two doublet peaks around $4.36 \mathrm{ppm}$ and two overlapping doublet peaks around $5.16 \mathrm{ppm}$, both of which have coupling constants of ${ }^{3} J_{\mathrm{aa}}=8.0 \mathrm{~Hz}$ and ${ }^{3} J_{\mathrm{ae}}=4.0 \mathrm{~Hz}$, respectively. These couplings of the anomeric protons $\left(\mathrm{H}_{\mathrm{a}}\right.$ and $\left.\mathrm{H}_{\mathrm{e}}\right)$ with the neighboring protons $(\mathrm{H})$ are indicated in the chemical structures. As for TEM-T9, NMR peaks corresponding to $\beta$ - and $\alpha$-anomeric protons $\left(\mathrm{H}_{\mathrm{a}}\right.$ and $\mathrm{H}_{\mathrm{e}}$, respectively) appear as individual peaks at 4.33 and $5.16 \mathrm{ppm}$, respectively, with the same $J$ values as observed for TSM-T9. (b, c) 2D NOESY NMR spectra of TSM-T9 and TEM-T9 dissolved in DMSO- $\mathrm{d}_{6}$. The main NOE correlation signals between the two protons in the linker region $\left(\mathrm{H}_{\mathrm{a}}-\mathrm{H}_{\mathrm{b}}, \mathrm{H}_{\mathrm{a}}-\mathrm{H}_{\mathrm{d}}, \mathrm{H}_{\mathrm{b}}-\mathrm{H}_{\mathrm{d}}\right.$ and $\mathrm{H}_{\mathrm{c}}-\mathrm{H}_{\mathrm{d}}$ for TSM-T9; $\mathrm{H}_{\mathrm{a}}-\mathrm{H}_{\mathrm{b}}$ and $\mathrm{H}_{\mathrm{a}}-\mathrm{H}_{\mathrm{c}}$ for TEM-T9) were assigned in the spectra. These correlations are indicated in red arrows in the chemical structures of TSM-T9 and TEM-T9. 


\section{Detergent comparison study with multiple membrane proteins}
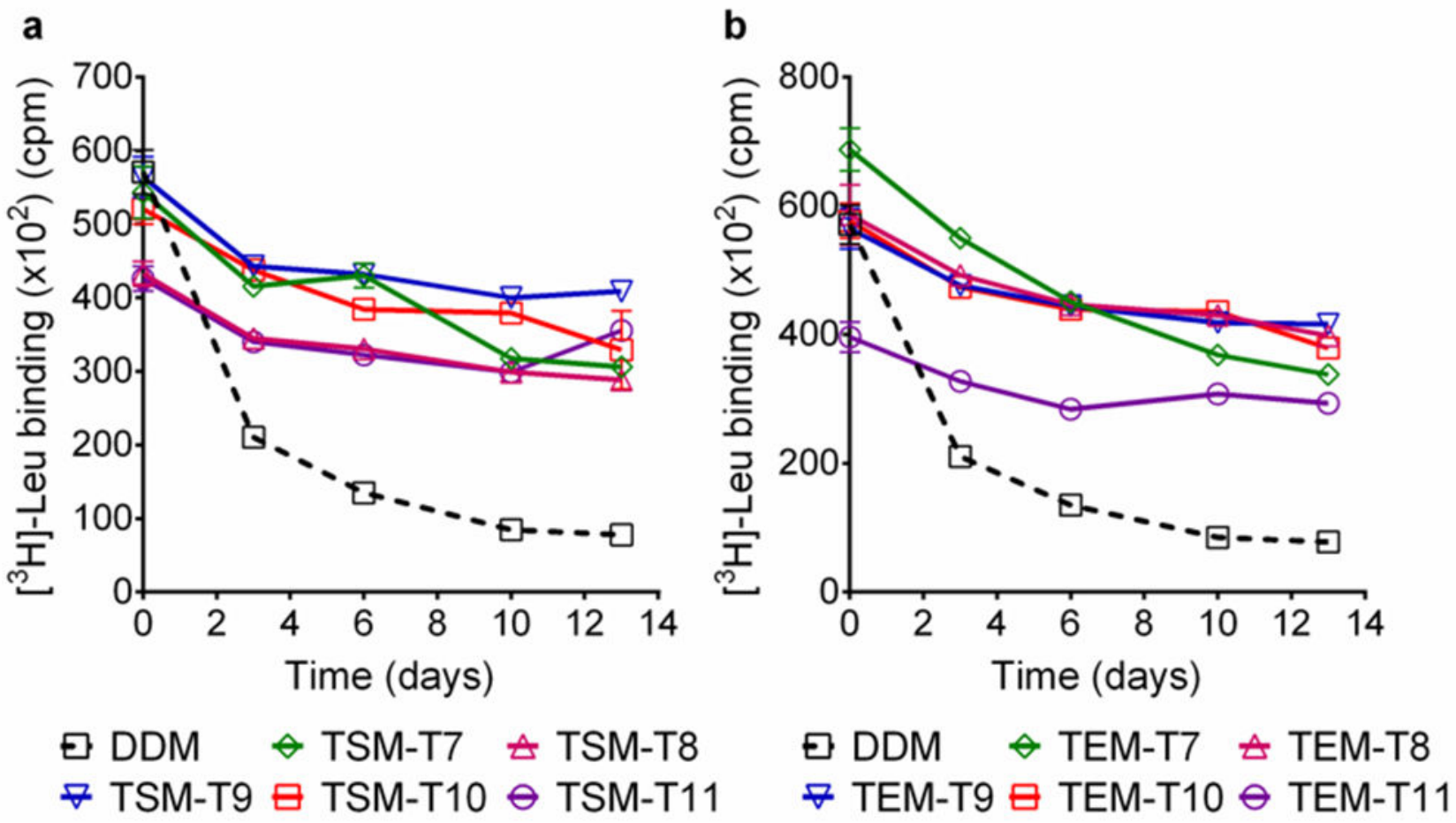

Fig. 3.

LeuT stability in (a) TSM-Ts and (b) TEM-Ts, using DDM as a control. The two sets of detergents were tested at $\mathrm{CMC}+0.04 \mathrm{wt} \%$. Scintillation proximity assay (SPA) was used to measure LeuT binding of the radio-labeled substrate $\left({ }^{3}[\mathrm{H}]\right.$-leucine $\left.(\mathrm{Leu})\right)$. The detergent samples were monitored at the designated time points during a 13-day incubation. Error bars: SEM, all experiments were performed in triplicate on two individual purifications. 

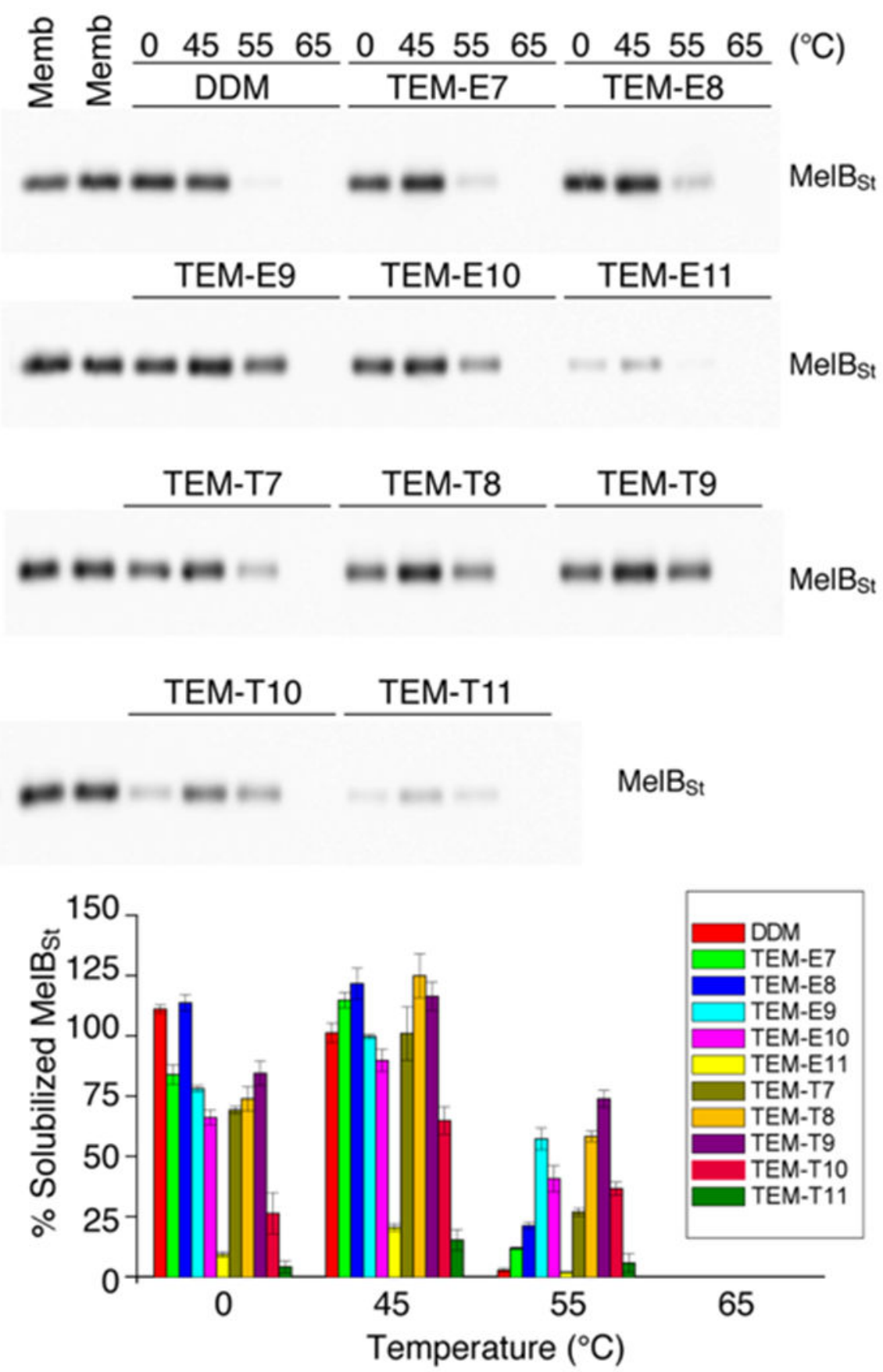

Fig. 4.

Thermo-solubility of MelB $_{\mathrm{St}}$ extracted in TEMs. A classical detergent (DDM) was used as a control. $\mathrm{MelB}_{\mathrm{St}}-$ containing $E$. coli membranes were treated with the individual TEMs at 0 ${ }^{\circ} \mathrm{C}$ for protein extraction. The detergent-extracted transporter was further incubated for 90 mins at a high temperature $\left(45,55\right.$, or $\left.65^{\circ} \mathrm{C}\right)$. The detergent extracts and thermally treated samples were subjected to ultracentrifugation before sample analysis via Western blotting (top panel). The amount of soluble $\mathrm{MelB}_{\mathrm{St}}$ in each detergent is represented as a relative 
amount (\%) of MelB $\mathrm{St}_{\mathrm{St}}$ present in the detergent-free membranes ('Memb') (bottom panel). Error bars, SEM, $n=2$. 


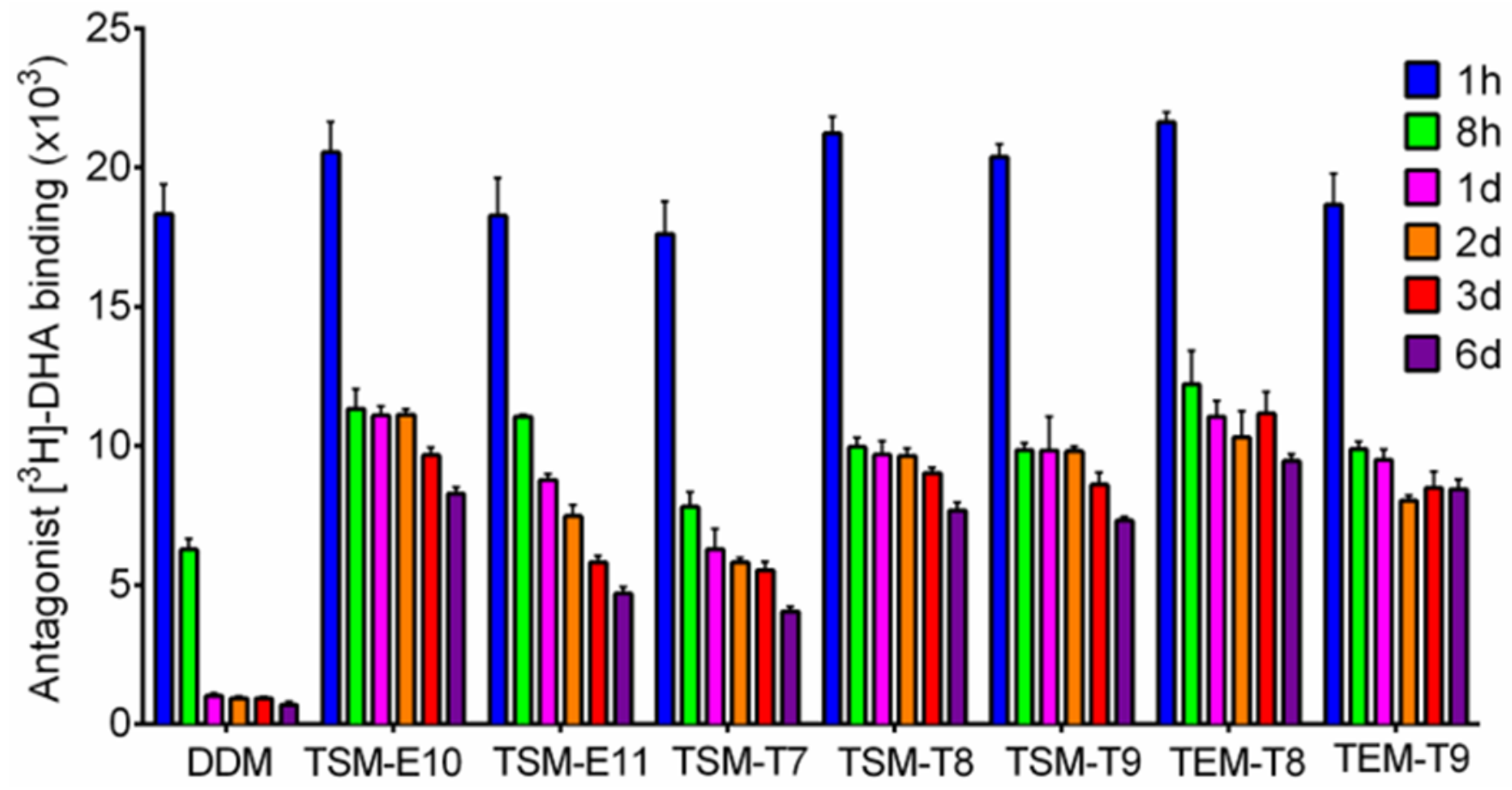

Fig. 5.

Time course ligand binding ability of $\beta_{2} \mathrm{AR}$ in selected TSMs/TEMs, or DDM. The individual detergents were used at $\mathrm{CMCs}+0.2 \mathrm{wt} \%$ for efficacy comparison. The radioactive antagonist $\left(\left[{ }^{3} \mathrm{H}\right]\right.$-dihydroalprenolol (DHA)) was used as a receptor-specific ligand. The receptor samples were incubated for 6 days at room temperature and protein stability assay was conducted at regular intervals during the incubation. Error bars, SEM, $n=3$. 

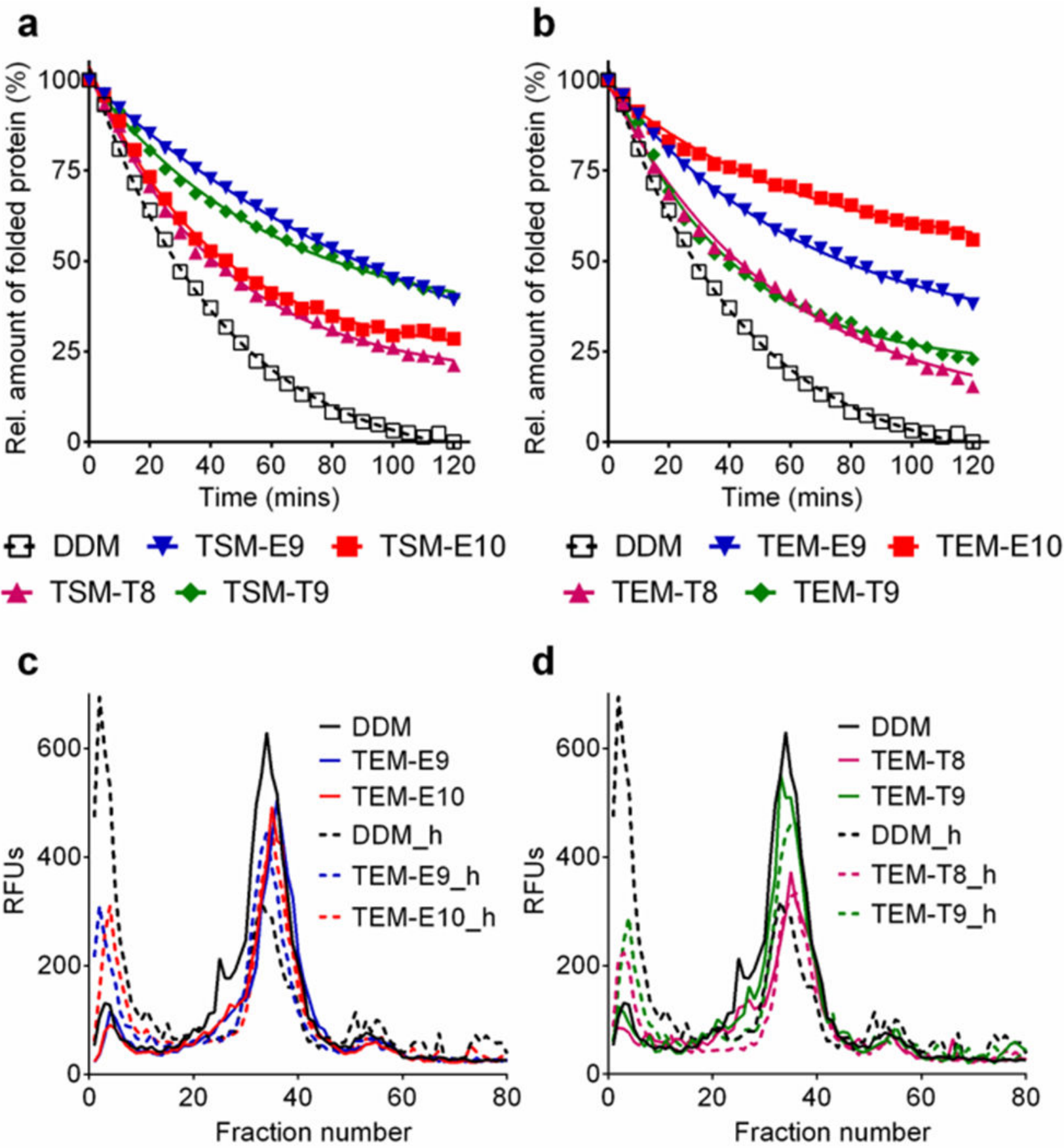

Fig. 6.

$(a, b)$ Normalized thermal denaturation profiles of AtBOR1 in selected TSMs (TSME9/E10/T8/T9) or TEMs (TEM-E9/E10/T8/T9) and (c,d) fluorescence size exclusion chromatography (FSEC) traces of AtBOR1-GFP fusion protein in the selected TEMs (TEME9/E10/T8/T9). DDM was used as a comparative detergent. Detergent ability to thermally stabilize the protein was monitored using the detergents at CMCs+0.04 wt\%. The CPM assay was used to measure relative amounts of folded transporter that were expressed after normalization to the worst conditions, corresponding in this case to DDM. FSEC traces were 
obtained from the fusion protein thermally treated at $47^{\circ} \mathrm{C}$ for $10 \mathrm{~min}$. Representative data from two independent experiments is shown. ' $h$ ' on the detergent label represents the heattreated sample. 


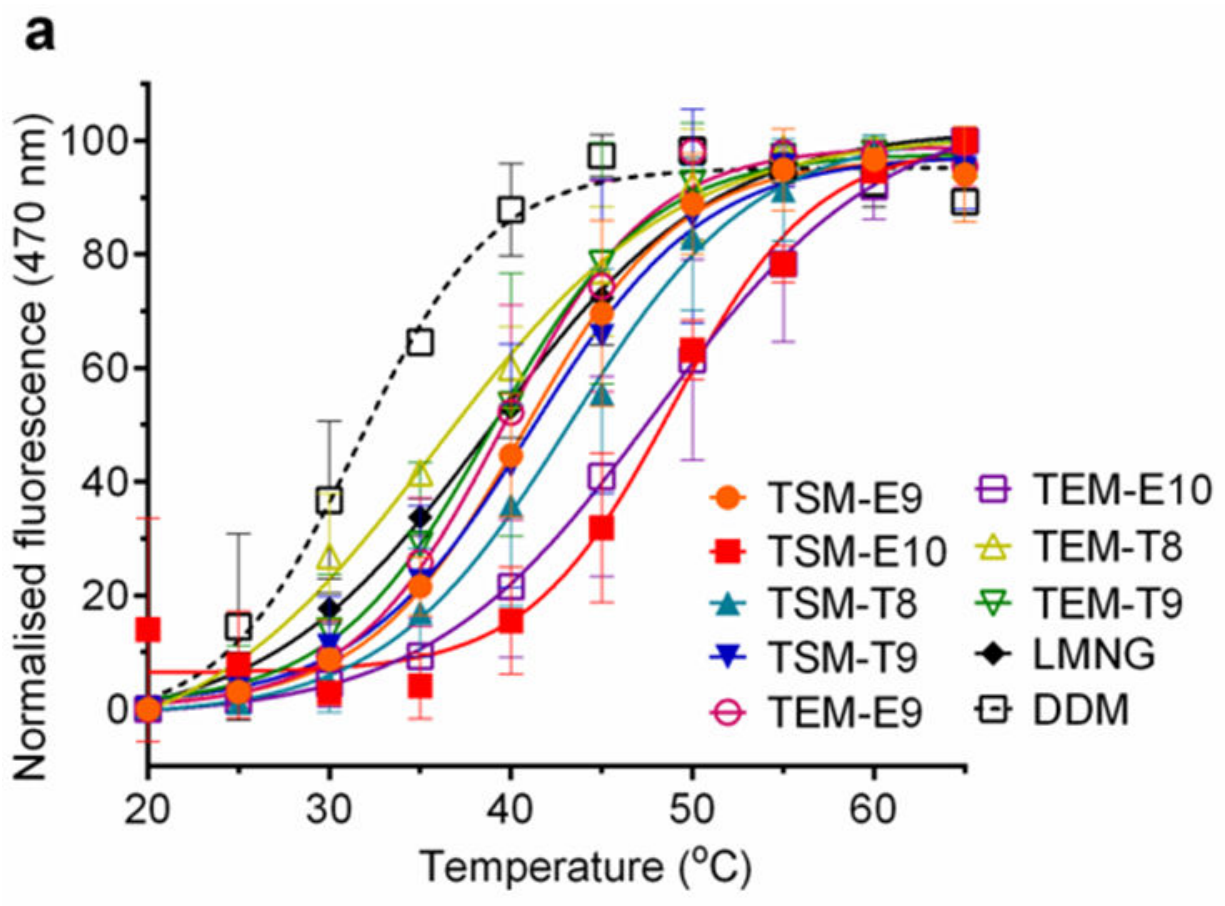

b

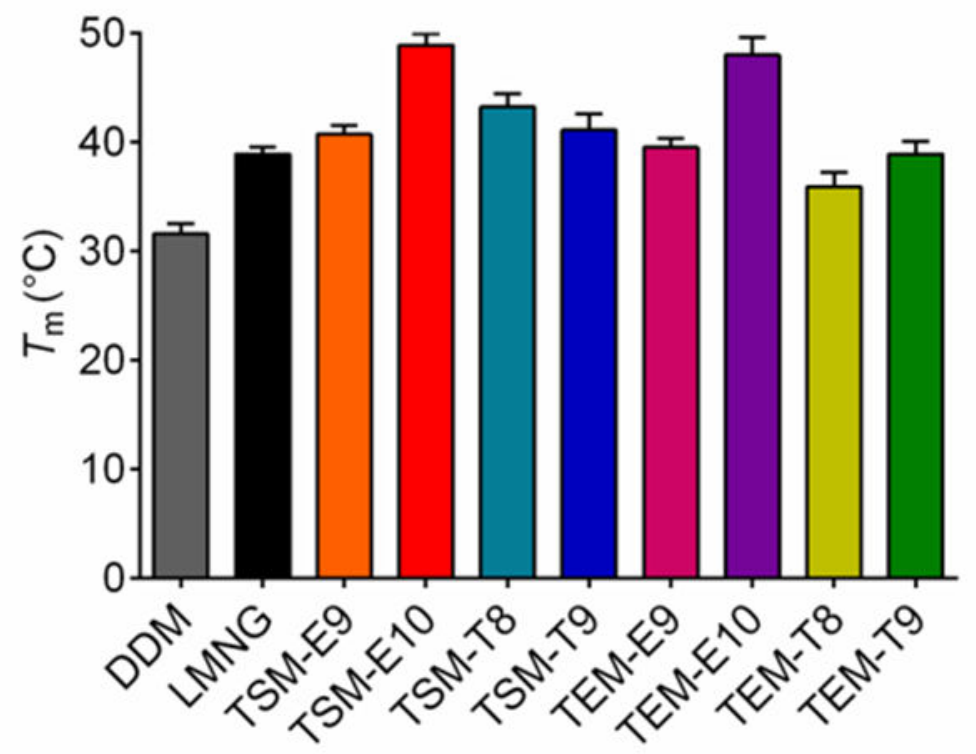

Fig. 7.

Thermal denaturation profiles of MOR (a) and resulting melting temperature $\left(T_{\mathrm{m}}\right)$ of the receptor in TSMs (TSM-E9/E10/T8/T9) and TEMs (TEM-E9/E10/T8/T9). DDM and LMNG were used to compare detergent efficacy. Temperature varied from 20 to $65^{\circ} \mathrm{C} . T_{\mathrm{m}}$ of the receptor was obtained via CPM assay using the detergents at $0.5 \mathrm{wt} \%$. Due to protein instability, CPM assay with the DDM-solubilized receptor was carried out without detergent exchange. Error bars, SEM; $n=2-3$. 


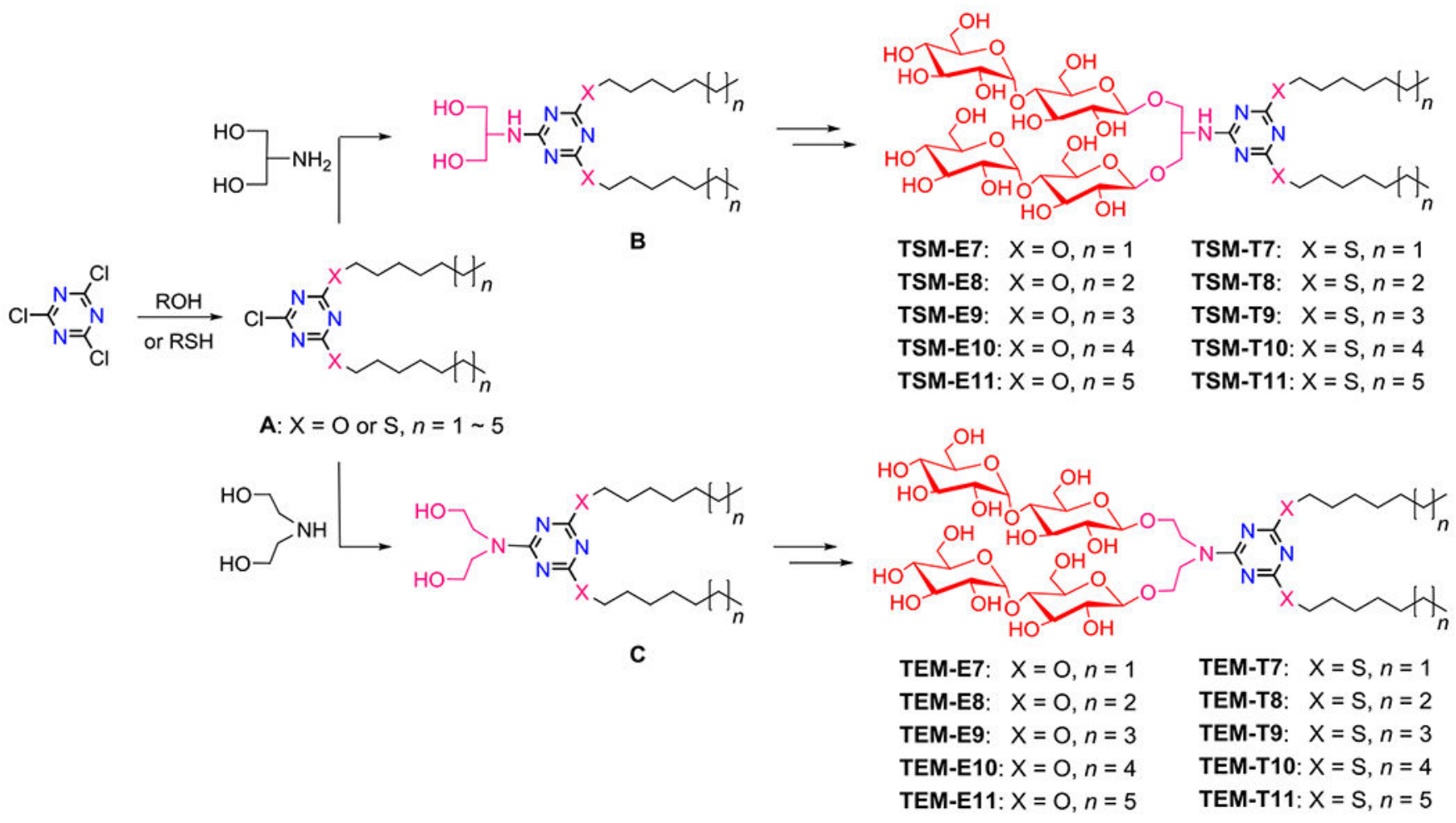

Scheme 1.

Synthetic schemes for generation of TSMs and TEMs. Two alkyl chains were introduced into the 1,3,5-triazine unit by reacting two equivalents of an alkanol (ROH; TSM-Es/TEM-

Es) or an alkanethiol (TSM-Ts/TEM-Ts) with cyanuric chloride. The dialkylated products with the ether or thioether linkage (A) were further modified by an amine-functionalized linker (serinol/diethanolamine (DEA) for the TSMs/TEMs), giving a dialkylated 1,3,5triazine-cored diol derivative $(\mathbf{B} / \mathbf{C})$. The resulting diol derivatives (B and $\mathbf{C}$ ) were additionally decorated with two maltose groups via $\beta$-stereoselective glycosylation and global deprotection, affording the final amphiphilic compounds (TSMs or TEMs). Variations in the amine-functionalized linker (serinol/DEA), alkyl linkage (ether/thioether) and the alkyl chain lengths (from C7 to $\mathrm{C} 11$ ) are indicated in the detergent designation. 


\section{Table 1}

Molecular Weights (MWs), Critical Micelle Concentrations (CMCs) of TSMs/TEMs/DDM, Detergent Micelle Sizes (Hydrodynamic Radii $\left(R_{\mathrm{h}}\right)$; mean \pm S.D., $\left.n=5\right)$ and Water Solubilities

\begin{tabular}{|c|c|c|c|c|}
\hline detergent & $\mathbf{M W}^{\boldsymbol{a}}$ & $\mathbf{C M C}(\boldsymbol{\mu M})$ & $\boldsymbol{R}_{\mathbf{h}}{ }^{\boldsymbol{}}(\mathbf{n m})$ & solubility \\
\hline TSM-E7 & 1047.1 & $\sim 40$ & $3.4 \pm 0.1$ & $\sim 10 \%$ \\
\hline TSM-E8 & 1075.2 & $\sim 20$ & $3.6 \pm 0.1$ & $\sim 10 \%$ \\
\hline TSM-E9 & 1103.2 & $\sim 10$ & $4.0 \pm 0.1$ & $\sim 10 \%$ \\
\hline TSM-E10 & 1131.3 & $\sim 4$ & $8.7 \pm 0.7$ & $\sim 5 \%$ \\
\hline TSM-E11 & 1159.3 & $\sim 2$ & $56.2 \pm 9.9$ & $\sim 1 \%$ \\
\hline TSM-T7 & 1079.2 & $\sim 10$ & $3.6 \pm 0.1$ & $\sim 10 \%$ \\
\hline TSM-T8 & 1107.3 & $\sim 6$ & $4.2 \pm 0.0$ & $\sim 10 \%$ \\
\hline TSM-T9 & 1135.3 & $\sim 4$ & $5.1 \pm 0.1$ & $\sim 10 \%$ \\
\hline TSM-T10 & 1163.4 & $\sim 3$ & $38.2 \pm 1.8$ & $\sim 5 \%$ \\
\hline TSM-T11 & 1191.5 & $\sim 1$ & $94.8 \pm 45$ & $\sim 1 \%$ \\
\hline TEM-E7 & 1093.3 & $\sim 30$ & $3.3 \pm 0.0$ & $\sim 10 \%$ \\
\hline TEM-E8 & 1121.3 & $\sim 20$ & $3.4 \pm 0.1$ & $\sim 10 \%$ \\
\hline TEM-E9 & 1149.4 & $\sim 9$ & $3.9 \pm 0.1$ & $\sim 10 \%$ \\
\hline TEM-E10 & 1177.4 & $\sim 5$ & $4.5 \pm 0.1$ & $\sim 5 \%$ \\
\hline TEM-E11 & 1205.5 & $\sim 1$ & $25.2 \pm 1.2$ & $\sim 1 \%$ \\
\hline TEM-T7 & 1125.4 & $\sim 8$ & $3.5 \pm 0.0$ & $\sim 10 \%$ \\
\hline TEM-T8 & 1153.4 & $\sim 4$ & $3.6 \pm 0.0$ & $\sim 10 \%$ \\
\hline TEM-T9 & 1181.5 & $\sim 3$ & $4.0 \pm 0.1$ & $\sim 10 \%$ \\
\hline TEM-T10 & 1209.5 & $\sim 2.5$ & $4.3 \pm 0.0$ & $\sim 5 \%$ \\
\hline TEM-T11 & 1237.6 & $\sim 1$ & $31.8 \pm 0.3$ & $\sim 1 \%$ \\
\hline DDM & 510.6 & 170 & $3.5 \pm 0.0$ & $\sim 10 \%$ \\
\hline
\end{tabular}

${ }^{a}$ Molecular weight of TSMs/TEMs/DDM.

${ }^{b}$ Micelle size estimated using $1.0 \mathrm{wt} \%$ detergent. 